\title{
A Study in Splitting the Ant Complex Monomorium antarcticum (Fr. Smith) (Hymenoptera: Formicidae).
}

\author{
Michael J. DANN \\ Ecology and Biodiversity \\ Victoria University of Wellington \\ Te Whare Wananga o te Upoko o te Ika a Maui
}

A thesis submitted as partial fulfilment for the degree of Masters of Science (MSc) in

2008 


\section{Preface}

This work provides new information about the native Southern Ant complex Monomorium antarcticum. In the first experimental chapter (chapter two) the diversity of species within the complex, the utility of DNA barcode molecular data in such taxonomic work and how DNA barcode data combines with traditional morphological and morphometric data is investigated. The second experimental chapter (chapter three) explores the genetic structuring of the complex and how that relates to the complexs recent biogeographic history and the dispersal potential, both natural and human mediated.

The two experimental chapters (chapters two and three) in this thesis have overlap of portions of the methods and results as they have been written as a pair of papers so as they can be read independently from each other.

In the appendix is a paper co-authored by the author of this thesis, which whilst not part of the requirements for this thesis provides further information relevant to the Monomorium antarcticum complex studied and was prompted from discoveries during the thesis research, the paper is currently under submission. 


\section{Acknowledgements}

Thanks to my supervisors, Philip J Lester and Peter A Ritchie for their advice and support during the duration of this thesis. Thanks to Barnaby Bennett for great company and help during the collection trip, thanks to P Sirvid and KC Burns for collecting and making available samples from Chatham Island. Thanks to the New Zealand Department of Conservation (DoC) for making samples available collected in the Nelson/Marlborough region, in particular thanks to I Millar. Thanks to the Victoria University of Wellington 'Bug Club' for comments on the manuscript. Thanks to S Greaves for advice in the laboratory. This research was supported by a grant to Michael Dann from the Tongariro Natural History Society. 


\section{Contents}

Preface..............................................................

Acknowledgements.................................................ii

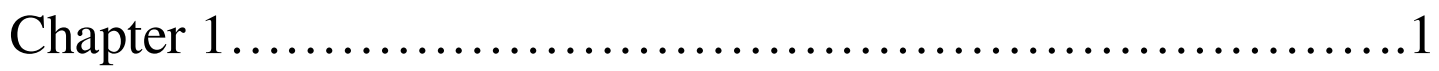

\section{General Introduction}

1. Species Diversity and Concepts of Species........................2

1.1 Species Diversity

1.2 Species Concepts

1.3 Species Complexes and Cryptic Species

2. Discovering Species......................................4

2.1. Traditional Taxonomic Techniques

2.2 Morphometrics in Taxonomy

2.3 Molecular Methods in Taxonomy

2.4 DNA Barcoding

3. Biogeography.

3.1 Phylogeography

3.2 Genetic Population Structuring

3.3 Phylogeography and Genetic Population Structuring of New Zealand Species

4. The Study Organism.

4.1 Monomorium (Hymenopetra: Formicidae) in New Zealand

5. Research Aims................................................... 12

6. References...................................................13 


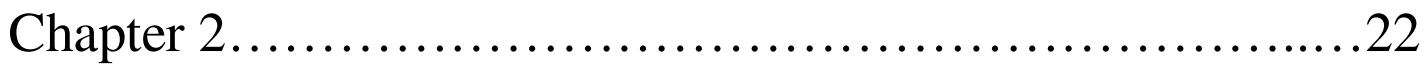

Searching for Species within Complexes: A Molecular and

Morphological study of the New Zealand Ant Complex

Monomorium antarcticum (Fr. Smith) (Formicidae:

Hymenoptera).

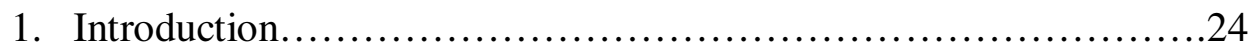

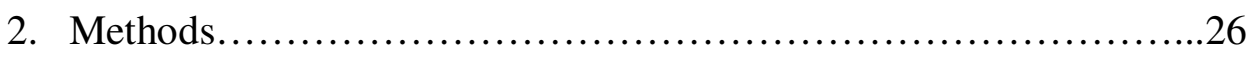

2.1 Collection of Samples

2.2 DNA Extraction, Amplifying and Sequencing

2.3 Molecular Data Analysis

2.4 Morphological Data

2.5 Morphometric Data

3. Results.

3.1 General Sequence/PCR Results

3.2 Molecular Groups

3.3 Morphological Groups

3.4 Morphometric Results

3.5 Integration of Molecular and Morphological Data

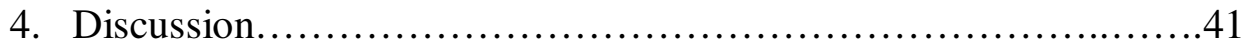

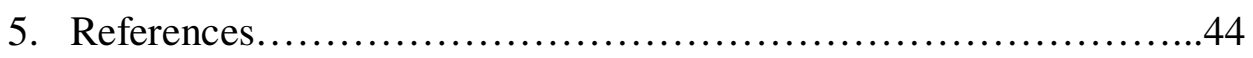


The Genetic Population Structuring of the Native Ant Complex Monomorium antarcticum (Fr. Smith) (Formicidae: Hymenoptera) within New Zealand based on Mitochondrial DNA: Insights into the how the Genetic Structuring Relates to Geography and Dispersal Potential.

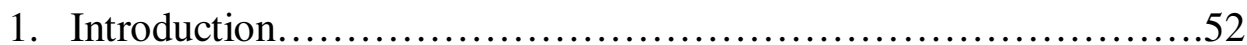

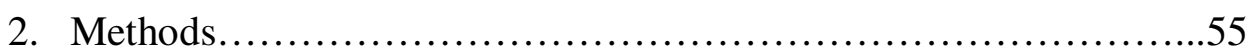

2.1 Collection of Samples

2.2 DNA extraction, Amplifying and Sequencing

2.3 Molecular Data Analysis

2.4 Phylogeny Construction

2.5 Morphological Data

2.6 Population Partitioning and Analysis of Molecular Variance

2.7 Isolation by Distance

2.8 Geographical Spread of Samples

3. Results

3.1 Phylogenies

3.2 Geographical Groups

3.3 Isolation by Distance

3.4 Analysis of Molecular Variance

4. Discussion. 69

5. References 


\section{General Discussion}

Implications from the work and Future Studies

1. Implications for the Native Ants of New Zealand. .80

1.1 Implications for the Monomorium antarcticum complex and the diversity of Native Ants in New Zealand

1.2 Processes contributing to the Low Ant (Hymenoptera:

Formicidae) Diversity in New Zealand

1.3 Human Mediated Dispersal of Monomorium antarcticum

1.4 Conservation Implications for New Zealand's Native Ants

2. Utility of Molecular Methods

2.1 Application of DNA Barcodes in Identifying New Species

2.2 Integration of Molecular and Morphological data

3. Further Studies .85

3.1 Future Studies on the Polygyny of the Monomorium antarcticum complex

4. References. 


\section{Chapter One}

General Introduction 


\section{Species Diversity and Species Concepts}

\subsection{Species Diversity}

Biodiversity is one of the overarching themes in biology, how many species, in which genus, family or phylum and where they exist or persist are some of the enduring questions in biology. Currently about 1.8 million species are formally identified (May, 1988; Minelli, 1993). Estimates of how many species there actually are range; from under five million to over 50 million (May, 1988). Compare that against that the rate of extinctions, there have been 724 known extinctions in the last 400 years (Reid, 1992). The existence of between two fifths and one twenty fifth of all species is recorded (depending of which estimate of total species to believe) and of those known species 724 have gone extinct in the last 400 years. It is possible to extrapolate those values, hence in that same time period between 1800 and 18000 species have gone extinct unrecorded. Many species are passing from extant to extinct without any formal record of their existence. Those are species which beyond their inherent natural and scientific worth may be key species in their ecosystems or may hold the secrets to novel and valuable chemical compounds.

\subsection{Species Concepts}

To discuss species numbers and diversity then it is fundamental to be clear about what a species is. Despite all the concern over species counts and extinction there is still not a universally accepted species concept, all biologists -and most of the public- understand in a practical sense what 'species' as a word refers to but at a precise level there is still evolution and redefinitions of the term (Stamos, 2003). The debate over how to define a species continues from the nineteenth century (Cracraft, 2000). The most common definition of a species is the biological species concept (and other related theories such as the Hennigian species concept) is based upon reproductive isolation and gene flow within the species (cohesion) (Mayr, 2000). A species is a group of "interbreeding natural populations that are reproductively isolated from other such groups" - Mayr 2000. That definition makes no mention of morphology, which the majority of species are defined upon, so potentially a species 
could be defined based upon the temporal separation of its reproductive 'window' when compared to a morphologically identical individual (Spaak et al., 2004). In that case the specific definition is based upon the actual factor that isolates the two individuals reproductively; practically a temporal difference in the reproductive window is no use in recognising those species apart from at that specific time, so typically morphological characters are used to distinguish species. When morphological characters are used (apart from characters based on reproductive organs) an assumption is made that a morphological difference in a certain structure is one of the factors -for example in mate recognition- or is a proxy for reproductive isolation (Mayr, 2000; Mishler and Theriot, 2000a; Vogler and Desalle, 1994).

It is important to note that the concepts of species are relative; each species needs a sister taxon with which to compare against. Species are formed from the emergence of a reproductive gap between sister species (Meier and Willmann, 2000). It is the isolation from it's closest relative that defines a species not its isolation from all other species. One of the main criticisms of the biological species concept is that it is based on reproductive isolation. Reproductive isolation is hard to directly observe in a natural setting (Knowlton et al., 1997; Mishler and Theriot, 2000a) and the concept ,being based upon reproductive isolation, does not apply well to asexual or parthenogenetic organisms (Templeton, 1989).

Other species concepts use criteria other than reproductive isolation or gene flow to define a species, making them theoretically applicable to all life forms regardless of reproductive process. For example the phylogenetic species concept (for which there are several versions, here an attempt at a general synthesis is used for brevity) is based on a species being the smallest recognisable group of organisms that have a shared ancestry (Mishler and Theriot, 2000b; Stamos, 2003; Wheeler and Platnick, 2000). Whilst differing in its defining factor, in its application the phylogenetic species concept is similar to the isolation and cohesion based species concepts, in that the species are assessed on morphology or molecular features and compared to the closest known relative. Another species definition is the evolutionary species concept, this concept is based upon the shared evolutionary fate of the organisms within a lineage and that those same organisms maintain their identity from other organisms not in the lineage (Simpson, 1951; Wiley and Mayden, 2000). Again the evolutionary species concept relies upon relativity; one group of organisms differences and maintained identity, comparative to another group. 
Spanning the debate over species concepts is the question of whether species are a natural concept; in that they are "objective or existing independently of the classifier" (Ruse, 1992) and that they are a units of evolution (Ereshefesky, 1992). Alternatively species are an approximation to a natural unit that is used to help us order nature (Ruse, 1992). The evolutionary species concept by definition tries to order species as evolutionary units, but like all the concepts it has an element of subjectivity; where is the line drawn on when individuals maintain their identity from others and the term 'evolutionary fate' is one open in interpretation. Regardless of whether species are truly natural or not as a concept - in any of their definitions they are entrenched in biology and useful as a concept to describe and discuss biodiversity.

\subsection{Species Complexes and Cryptic Species}

Species complexes are a group of two or more closely related, probably sibling, species (Knowlton, 1993). Species complexes are often, but not by definition, composed of cryptic species. Cryptic species are those than cannot be easily defined using morphology (Bastrop et al., 1998; Mayr and Ashlock, 1991; Morehead et al., 2001). They appear indistinguishable (to us) from each other. Species complexes are probably more common than is currently recorded as they have mostly been recognised in taxa with human importance as they are the target of more research compared to the majority of taxa. For example the Malaria mosquito Anopheles gambiae (Coetzee et al., 2000; Collins and Hill, 2005) and the whitefly Bemisia tabaci (Brown et al., 1995) were discovered as cryptic species complexes after considerable work. 


\section{Discovering Species}

\subsection{Traditional Taxonomic Techniques}

Taxonomy, the description and cataloguing of the diversity of life (Quicke, 1997), is one of the oldest natural sciences. Aristotle was describing and naming 'species' in the $3^{\text {rd }}$ century BC (Mayr, 1982), albeit with none of the scientific rigor used today. Traditional taxonomy includes the naming of taxa (nomenclature), the arrangement of taxa within the classificatory framework and the identification and description of new taxa. It is the identification of new species that I will be concentrating on in this work, as the classification of the study group of this work is already well settled. The traditional taxonomic process is based upon identifying characters that vary amongst the study group of related species. The characters are typically morphological, but behavioural characters are also used, each state of the character is prescribed a code and each sample is assessed for each character. The result is a matrix of character states which is used to either differentiate the samples or group them together depending on the combination of character states each possess and which character states are deemed important. That 'ranking' of characters is one of the processes that make taxonomy somewhat subjective, another being that many fields of taxonomy are so specialised. Most fields of taxonomy require a degree of prior knowledge of the taxa being studied hence a certain amount of trust must be invested in the taxonomist that they are being prudent with their conclusions as very few people have the skills and knowledge to dispute their conclusions.

\subsection{Morphometrics in Taxonomy}

Morphometrics is one potential answer to the problem of subjectivity (Blackith and Reyment, 1971). Various measurements of structural features of the organisms studied are made, the ratios and or comparative values of the measurements are analysed using statistics (Blackith and Reyment, 1971; Zelditch et al., 2004) and the samples are again differentiated or coalesced depending on the results. Morphometrics have been applied to fossil records to help identify 
incomplete samples (Elewa, 2004), to detect hybrid zones (Lambert et al., 2006; Luebke et al., 1988) but it has also been useful in identifying new insect species (Daly, 1985; Patterson et al., 2001). In insects, morphometrics is of particular utility when trying to delineate two very similar morphological species which may differ slightly in the size or ratio of various body structures (Meunier et al., 1999). Whilst morphometrics does remove some of the subjectivity of taxonomy, in that it reduces a potentially complex character into a quantitative continuous numerical value, the selection on what to measure still has an element of subjectivity.

\subsection{Molecular Methods in Taxonomy}

The use of molecular data in taxonomic studies is not new. Enzymes have been used in the past as diagnostic characters when morphology was not sufficient (Ayala and Powell, 1972). The use of actual sequences of DNA is a more recent technique in taxonomic biology (Kocher et al., 1989). It involves the sequencing of segments of nuclear or mitochondrial DNA (mtDNA). Those sequences are compared looking for differences between the sequences that can be used to differentiate the samples the sequences were extracted from. DNA sequences in taxonomy are typically viewed as another tool, alongside morphology, to be used in detecting and describing species. DNA sequences are thought to be particularly helpful in taxa with a degree of morphological crypsis such as displayed by cryptic species (Paquin and Hedin, 2004).

\subsection{DNA Barcoding}

Firstly, the conceptual difference between DNA barcoding and molecular taxonomy must be noted. The term 'DNA barcode' has some implications in regards to the methodological basis of the study; it implies the application of the mtDNA barcode in isolation from other taxonomic tools such as morphology. DNA barcoding is one of the newest and most controversial molecular tools in taxonomy. In essence barcoding is the proposition that any species could be identified using a universal, short (about 500 base pair) stretch of DNA sequence of the mitochondrial genome (Hebert et al., 2004a). The technique compares the barcode to an existing database of barcodes. New species could be identified by comparing their DNA 
barcode to the barcode of their closet relative. The concept of a using a standard region of mtDNA to be used across all animal taxa is DNA barcoding's major strength and perhaps its major weakness. DNA barcoding does have many positive features. Barcoding reduces the need for specialist taxonomic knowledge; as it is relatively easy to extract and sequence a section of DNA. Barcoding does not need intact samples, as a DNA sequence can be extracted from a single leg of a fly for instance, museum samples can be compared to freshly collected ones and the collection of large sample sizes is not necessarily required. Hence the identification of new species will hopefully accelerate (Moritz and Cicero, 2004). For animals a fragment of the Cytochrome Oxidase One region (COI) is proposed as the universal barcode (Hebert et al., 2004a).

It is the idea of applying DNA barcoding to the discovery of new species that has generated the most discussion. When used as a tool in discovering new species a sequence threshold must be applied to the sequence data. A sequence threshold is a set percentage where if two samples have less genetic distance between them tham the preset threshold then they are considered to belong to the same species, but if they genetic distance is more than the threshold then they are considered different species (Hebert et al., 2004a; Hebert et al., 2004b). The threshold concept relies on the assumption that inter-specific variation is greater than intra-specific variation.

DNA barcoding, whilst a promising tool for accelerating the discovery and identification of species, does have several criticisms. Firstly the lack of a true universal barcode, no any one barcode will have low intraspecific variation and high interspecific variation across all animals (Meier et al., 2006; Nielsen and Matz, 2006). Some critics claim that the barcoding 'gap' between intra and inter specific is an artefact of poor sampling and the 'gap' disappears with a large sample (Wiemers and Fiedler, 2007). In many ways the sequence threshold approach to species discovery is too simplistic, ignoring the possibility of different species having different rates of evolution for the $\mathrm{COI}$ region or that the $\mathrm{COI}$ region may be highly conserved in some species (Huang et al., 2008). A standard percent sequence difference will not work consistently when used in a taxonomic vacuum; some prior knowledge of the diversity of the groups studied is required as a comparison with which to gauge the appropriate threshold to use. Even proponents of barcoding require a traditional taxonomic framework with which to test barcoding against (Hebert et al., 2004b). Sampling within the mitochondrial genome (mtGenome) is 
also a issue, a barcode of around 500 base pairs is only 3 percent of the entire 16500 base pairs of an insect mtGenome (Stewart and Beckenbach, 2004). A general opinion of those that advise caution over the use of DNA barcodes alone is that to work with any accuracy the barcodes must be used against a solid taxonomic structure (Meyer and Paulay, 2005). However despite all the criticism and problems that DNA barcoding seems to have it is still an exciting prospect for future taxonomy. It is positive that so many potential problems have been recognised as it will make further work more robust and hopefully more biologically accurate.

\section{Biogeography}

\subsection{Phylogeography}

DNA sequences can be used for much more than identifying organisms or diagnosing new species. MtDNA sequences have an aspect of time associated with them. Phylogeography studies how a molecular phylogeny relates to past and present geographical processes or geographical structure (Avise, 1998; Hewitt, 2001; Taberlet et al., 1998). The term phylogeography was coined in 1987 (Avise et al., 1987), but as a study it has a longer history with a basis in biogeography and the theory of plate tectonics (Avise, 1993). Biogeography, the study of where and when

species exist, dates as far back as Alfred Wallace in the $19^{\text {th }}$ century (Wallace, 1860). MacArthur and Wilson updated the study in the mid $20^{\text {st }}$ century making it more analytical and current rather than purely descriptive and historical (MacArthur and Wilson, 1967). In a sense phylogeography is an extension of biogeography using DNA as means to test the 'whys' of biogeography. With the appropriate DNA sequences and the range of analysis available it may be possible to determine what geographic features or processes are important in determining the current distribution of species. At the time Avise coined the term, the theoretical basis of phylogeography was not novel but the means to test it on a large scale were just becoming possible, both financially and practically with the advent of high thru-put sequencers.

Underpinning biogeography and phylogeography is the concept of allopatric speciation, the modern theory of which was developed by Mayr $(1954,1963)$. In 
allopatric speciation a group of organisms belonging to the same species are separated by a geographical barrier, a sea, river, mountain range, glacier, desert or one of many others. In isolation, and without any interbreeding, the two groups evolve intrinsic barriers to reproduction such that the geographical barrier is no longer needed to prevent interbreeding of the two groups; a new species is formed.

The basic techniques of phylogeography are as follows; firstly construct a phylogeny of a one or more species based on one or several genes, then apply a molecular clock to gain as aspect of time (if necessary and or relevant) to the phylogeny and then consider how the patterns within the phylogeny are consistent or contrast with potential historical geographical processes. What historical processes could explain the structure observed in the phylogeny? Alternatively one can form a theory of a historical geographical process and construct a phylogeny to test that theory.

A classic example of phylogeography is the colonisation of the Hawaiian archipelago. As new islands emerged via volcanism from the sea they were subject to repeated colonisation from the older islands, hence there is a common pattern of the newest species inhabiting the newest islands (Roderick and Gillespie, 1998). Phylogeography can be also be applied in the aquatic environment, a classic example of this is the cichlid fish that inhabit lakes of eastern Africa. Historical fluctuations in the lake levels have separated the lakes into several smaller lakelets each with its own isolated population of cichlid fishes. Modern populations of several cichlid species display clades and or male colouration patterns corresponding to the number of lakelets the lake was divided into when the water level fell (Baric et al., 2002; Smith and Kornfield, 2002; Verheyen et al., 1996).

\subsection{Genetic Population Structuring}

Population Structuring is not fundamentally different from phylogeography. The major difference is the scale is it applied on and the types of processes it can reveal. Population structuring can be considered intraspecific phylogeography (Avise et al., 1987). Whilst phylogeography works with whole species as units of population structuring - as the name suggests - population structuring ndeals with the subdivisions within a species, going as detailed as individual haplotypes (O'CorryCrowe et al., 1997; Templeton et al., 1995). Like phylogeography the genetic 
structuring seen in the populations is often related to the current or historical geographical processes, or alternatively past geographic processes are inferred from the structuring seen in the modern population. In general population structuring deals with a more recent time frame than phylogeography due to the structuring of an individual population being more recent than the divisions between species. Genetic population structuring imparts a layer of detail genetic beyond most phylogeographic studies; it can give insights into the dispersal power and patterns of the organism in question. Such is the detail that haplotyope networks, a 'map' of the connections (down to a single base pair change) between haplotypes, can be constructed. A haplotype network can inform about the relationships between different populations, for example which populations are interbreeding (Johnson et al., 2002). A network can help identify population bottlenecks and the subsequent expansion from that locality (Meyers et al., 2000) and dispersal routes of organisms particularly in invasive species such as the Argentine ant (Linepithema humile) (Corin et al., 2007) and an invasive brittlestar (Roy and Sponer, 2002). The dispersal potential of an organism can be inferred once a layer of geographic data is added to the genetic data (Bohonak, 1999; Wishart and Hughes, 2003). The further apart and more genetically similar samples (or populations) are then presumably the faster and further the organisms within the population are dispersing. That is the essence of the isolation by distance concept (Wright, 1943). It relates the genetic distance between samples to the geographic distance between that same pair of samples.

\subsection{Phylogeography and Genetic Population Structuring of New Zealand Species}

New Zealand has a rich scientific history of phylogeography and genetic population structuring, a quick search of journals with an engine such as 'Web of Science' results in hundred of articles focussing on the phylogeography and genetic population structuring of New Zealand and its biota. New Zealand has had a long history of isolation. It is generally thought to have broken away from Australia and the rest of Gondwana around 80 million years ago (mya) (Cooper and Millener, 1993), taking with it all manner of ancient animals - the tuatara and velvet worm (Onychophora) - and plants. Hence all biota was either present on Zealandia (the piece of land that broke away from Gondwana which included present day New 
Zealand and New Caledonia amongst others) or it reached here transoceanicly in the intervening years. Recently there has been some postulating that model of gondwana drift was not the case, or rather not the whole story. It is proposed that New Zealand was completely submerged at some point between 85-22 mya and that New Zealand only emerged permanently from the sea to accept the biota present today around 22 mya (Landis et al., 2008; Pole, 1994). Other earlier work (Landis et al., 2008) accepted the major reduction of land mass of New Zealand due to sea level rises but none had proposed a complete submersion of all land or 'drowning'. That drowning, referred to as the Oligocene drowning, is proposed as responsible for many bottlenecks and structuring of populations in New Zealand (Cooper and Cooper, 1995; Stöckler et al., 2002).

However the origins of New Zealand's biota - Gondwanan or oceanic - does not change its more recent history. Some of the common themes of the phylogeographic and population structuring studies of New Zealand flora and fauna include the classic glacial refugia theory (Trewick and Wallis, 2001; Wardle, 1988), the vicariance or dispersal of flora and fauna to the Chatham Islands $(800 \mathrm{~km}$ off the east coast of the South Island) (Emberson, 1995; Trewick, 2000). Other common themes in New Zealand phylogeographic and population structuring studies include the separation (or continuity) between North and South Island taxa, as in some kiwi species (Baker et al., 1995). The high degree of movement of the tectonic plates underneath New Zealand resulting in the formation of the Southern Alps since the Oligocene drowning is another common theme as is the "Beech Gap". The "Beech Gap" is an area on the southern west coast of the South Island of New Zealand which is devoid (a disjunction of distribution) of many species that occur on the northern and southern side of the gap. The gap has been attributed to either tectonic processes (Heads, 1998) or glacial events (Willett, 1950).

\section{The Study Organism}




\subsection{Monomorium (Hymenoptera: Formicidae) in New Zealand}

There is an amazing diversity of ants. There are 11477 extant described species (Bolton et al., 2006). Ants are a fascinating taxonomic subject due to their generally conspicuous nesting behaviour, sheer numbers of individuals and the curiosity their complex social structure inspires in humans (Don, 2007). Only 38 of those 11477 species inhabit New Zealand; just eleven are natives (Ward, 2005) and three of those natives belong to the genus Monomorium. Worldwide the genus has over 550 species and subspecies, six of those inhabit New Zealand

The most common and ubiquitous of the native ants is Monomorium antarcticum (Fr. Smith) commonly called the Southern Ant (Brown, 1958). It is present across all of New Zealand including Stewart Island, the Chatham Islands and the Three Kings Islands (Brown, 1958; Don, 1994; Don, 2007). Monomorium antarcticum is considered a complex of sibling species rather than a single distinct species (Brown, 1958; Don and Jones, 1993; Wang and Lester, 2004). Though considered endemic (Ward, 2005) there is a record of samples from Raul Island in French Polynesia (Wheeler, 1936). That record, in this author's opinion, is unlikely to be the same species as $M$. antarcticum rather when using the current key for the group. Those samples from Raul appear the same as $M$. antarcticum. An attempt was made to secure samples of that Monomorium species from Raul to include in this study but as yet no samples have been secured. Monomorium antarcticum is a relatively unremarkable looking ant. The workers are about 3-4mm outstretched in length (Brown, 1958), vary in colour from a deep glossy black to a vivid almost translucent orange and through shades of orange and brown (Brown, 1958; Don, 2007). They live in colonies ranging from a single queen with a retinue of less than a hundred workers up to a nest presided over by multiple queens (called polygyny; the author has observed 9 queens present in one nest) and excess of a thousand workers. It is not uncommon to find $M$. antarcticum cohabiting a nest site such as under a rock, where nests are often found, with another native ant species such as M. smithii or Huberia striata (Lester et al., 2008). During New Zealand's late summer (February and March) M. antarcticum can be seen in large mating swarms (Smith, 1895). They are generalist feeders preying upon small invertebrates, are thought to collect seeds (Don, 2007) and other plant matter and they can be observed 'milking' 
homopterans such as 'mealy bugs' (Brown, 1958; Don, 2007; Lester et al., 2008; Smith, 1895). The range of colours displayed by $M$. antarcticum in conjunction with diversity in several structural features has led to the complex being divided into five or more 'species' (Brown, 1958) based on various characters within that diversity. Work has also been done to try and find additional means to delineate the complex. These include chemotaxonomy of the venom (Don and Jones, 1993; Jones et al., 1986) and the morphometrics of several key measurements of the workers (Wang and Lester, 2004). Both cited studies found evidence for a complex however neither was aiming to try and propose an answer on how to split the complex.

\section{Research Aims}

The aims of this research are to attempt to discover the species diversity within the Monomorium antarcticum complex using both molecular data in the form of DNA barcodes and morphological features. More broadly, I hope from that species diversity to gain some insights into the degree of differentiation necessary between two organisms for them to be defined as different species, as the species within complexes are usually very closely related. Furthermore I hope to assess the utility of DNA barcoding in trying to delineate species and how DNA barcodes are consistent, with or conflict with, morphological data. This research also aims to provide some insights into the population structuring of the complex, and the dispersal potential of the $M$. antarcticum complex. 


\section{References}

Avise, J.C., 1993. Molecular markers, natural history and evolution. Kluwere Academic Publishers.

Avise, J.C., 1998. The history and purview of phylogeography: A personal reflection. Molecular Ecology 7, 371-379.

Avise, J.C., Arnold, J., Ball, R.M., Bermingham, E., Lamb, T., Neigel, J.E., Reeb, C.A., Saunders, N.C., 1987. Intraspecific phylogeography: The mitochondrial DNA bridge between population genetics and systematics. Annual Review of Ecological Systematics 18, 489-522.

Ayala, F.J., Powell, J.R., 1972. Allozymes as diagnostic characters of sibling species of drosophila. Proceedings of the National Academy of Sciences of the United States of America 69, 1094-1096.

Baker, A., Daugherty, C.H., Colbournes, R., McLennan, J.L., 1995. Flightless brown kiwis of new zealand possess extremely subdivided population structure and cryptic species like small mammals. Evolution 92, 8254-8258.

Baric, S., Salzburger, W., Sturmbauer, C., 2002. Phylogeography and evolution of the tanganyikan cichlid genus tropheus based upon mitochondrial DNA sequences. Journal of Molecular Evolution 56, 54-68.

Bastrop, R., Jurss, K., Sturmbauer, C., 1998. Cryptic species in a marine polychaete and their independent introduction from north america to europe. Molecular Biology and Evolution 15, 97-103.

Blackith, R.E., Reyment, R.A., 1971. Multivariate morphometrics. Academic Press, London and New York.

Bohonak, A.J., 1999. Dispersal, gene flow, and population structure. The Quarterly Review of Biology 74, 21-45.

Bolton, B., Alpert, G., Ward, P.S., Naskrecki, P., 2006. Bolton's catalogue of ants of the world, 1758-2005. Cd rom. Harvard University Press.

Brown, J.K., Frohlich, D.R., Rosell, R.C., 1995. The sweetpotato or silverleaf whiteflies: Biotypes of bemisia tabaci or a

species complex? Annual Review of Entomology 40, 511-534.

Brown, W.L.J., 1958. A review of the ants of new zealand. Acta Hymenopterologica 1, 1-50. 
Coetzee, M., Craig, M., Sueur, D.1., 2000. Distribution of african malaria mosquitoes belonging to the anopheles gambiae complex. Parasitology Today 16, 74-77.

Collins, F.H., Hill, C.A., 2005. The anopheles gambiae genome. In: Sherman, I.W. (Ed.), Molecular approaches to malaria. ASM Press, Washington D.C.

Cooper, A., Cooper, R.A., 1995. The oligocene bottleneck and new zealand biota: Genetic record of a past enviromental crisis. Proceedings of the Royal Society of London: Biology 261, 293-302.

Cooper, R.A., Millener, P.R., 1993. The new zealand biota: Historical background and new research. Trends in Ecology and Evolution 8, 429-433.

Corin, S.E., Lester, P.J., Abbott, K.L., Ritchie, P.A., 2007. Inferring historical introduction pathways with mitochondrial DNA: The case of introduced argentine ants (linepithema humile) into new zealand. Diversity and Distributions 13, 510-518.

Cracraft, J., 2000. Species concepts in theoretical and applied biology: A systematic debate with consequences. In: Wheeler, Q.D., Meier, R. (Eds.), Species concepts and phylogentic theory: A debate. Columbia University Press, New York, pp. 3-16.

Daly, H.V., 1985. Insect morphometrics. Annual Review of Entomology 30, 415-438.

Don, A.W., 1994. Ants (hymenoptera: Formicidae) from three kings islands, new zealand. New Zealand Entomologist 17, 22-29.

Don, A.W., Jones, T.H., 1993. The stereochemistry of 3-butyl-5-(5-hexenyl)pyrrolizidine from population of monomorium antarcticum (smith) (hymenoptera: Formicicdae) and its possible role as a unique taxonomic character. New Zealand Entomologist 16, 45-48.

Don, W., 2007. Ants of new zealand. Otago University Press, Dunedin.

Elewa, A.M.T. (Ed.), 2004. Morphometrics : Applications in biology and paleontology. Springer, Berlin; New York.

Emberson, R.M., 1995. The chatham islands beetle fauna and the age of separation of the chatham islands from new zealand. New Zealand Entomologist 18, $1-7$.

Ereshefesky, M., 1992. Species, higher taxa, and the units of evolution. In: Ereshefsky, M. (Ed.), The units of evolution: Essays on the nature of species. Bradford, Cambridge. 
Heads, M., 1998. Biogeographic disjunction along the alpine fault, new zealand. Biological Journal of the Linnean Society 63, 161-176.

Hebert, P.D.N., Penton, E.H., Burns, J.M., Janzen, D.H., Hallwachs, W., 2004a. Ten species in one: DNA barcoding reveals cryptic species in the neotropical skipper butterfly astrapes fulgerator. Proceedings of the National Academy of Sciences 101, 14812-14817.

Hebert, P.D.N., Stoeckle, M.Y., Zemlak, T.S., Francis, C.M., 2004b.

Identification of birds through DNA barcodes. Public Library of Science Biology 2, 1657-1663.

Hewitt, G.M., 2001. Speciation, hybrid zones and phylogeography - or seeing genes in space and time. Molecular Ecology 10, 537-549.

Huang, D., Meier, R., Todd, P.A., Chou, L.M., 2008. Slow mitochondrial coi sequence evolution at the base of the metazoan tree and its implications for DNA barcoding. Journal of Molecular Evolution 66, 167-174.

Johnson, K.P., Williams, B.L., Drown, D.M., Adams, R.J., Clayton, D.H., 2002. The population genetics of host specificity: Genetic differentiation in dove lice (insecta: Phthiraptera). Molecular Ecology 11, 25-38.

Jones, T.H., Highet, R.J., Don, A.W., Blum, M.S., 1986. Alkaloids of the ant chelaner antarcticus. Journal of Organic Chemistry 51, 2712.

Knowlton, N., 1993. Sibling species in the sea. Annual Review of Ecological Systematics 24, 189-121.

Knowlton, N., Mate, J.L., Guzman, H.M., Rowan, R., Jara, J., 1997. Direct evidence for reproductive isolation among the three species of the montastraea annularis complex in central america (panama and honduras). Marine Biology 127, 705-711.

Kocher, T.D., Thomas, W.K., Meyer, A., Edwards, S.V., Paabo, S., Villablanca, F.X., Wilson, A.C., 1989. Dynamics of mitochondrial DNA evolution in animals: Amplification and sequencing with conserved primers. Proceedings of the National Academy of Sciences 86, 6196-6200.

Lambert, S.M., Borba, E.L., Machado, M.C., 2006. Allozyme diversity and morphometrics of the endangered melocactus glaucescens (cactaceae), and investigation of the putative hybrid origin of melocactus $x$ albicephalus (melocactus ernestii x m. Glaucescens) in north-eastern brazil. Plant Species Biology 21, 93-108. 
Landis, C.A., Campbell, H.J., Begg, J.G., Mildenhall, D.C., Paterson, A.M., Trewick, S.A., 2008. The waipounamu erosion surface: Questioning the antiquity of the new zealand land surface and terrestrial fauna and flora. Geological Magazine $145,173-197$.

Lester, P.J., Dann, M.J., Ritchie, P.A., 2008. Coexistence and the use of habitat resources in a new zealand sub-alpine ant community (Hymenoptera: Formicidae). Submitted Research. Victoria University of Wellington, Wellington.

Luebke, H.J., Scriber, J.M., Yandell, B.S., 1988. Use of multivariate discriminant analysis of male wing morphometrics to delineate a hybrid zone for papilio glaucus glaucus and P. G. Canadensis in wisconsin. American Midland Naturalist 119, 366-379.

MacArthur, R.H., Wilson, E.O., 1967. The theory of island biogeography. Princeton University Press, Princeton, N.J.

May, R.M., 1988. How many species? Science 241, 1441-1449.

Mayr, E., 1954. Change of genetic environment and evolution. George Allen \& Unwin Ltd.

Mayr, E., 1963. Animal species and evolution. Belknap Press of Harvard University Press.

Mayr, E., 1982. The growth of biological thought: Diversity, evolution and inheritance. The Belknap Press of Havard University Press, Cambridge.

Mayr, E., 2000. The biological species concept. In: Wheeler, Q.D., Meier, R. (Eds.), Species concepts and phylogenetic theory : A debate. Columbia University Press, New York, pp. 17-29.

Mayr, E., Ashlock, P.D., 1991. The principles of systematic zoology. McGraw Hill, New York.

Meier, R., Shiyang, K., Vaidya, G., Ng, P.K.L., 2006. DNA barcoding and taxonomy in diptera: A tale of high intraspecific variability and low identification success. Systematic Biology 55, 715-728.

Meier, R., Willmann, R., 2000. The hennigian specis concept. In: Wheeler, Q.D., Meier, R. (Eds.), Species concepts and phylogentic theory: A debate.

Meunier, L., Dalecky, A., Berticat, C., Gaume, L., McKey, D., 1999. Worker size variation and the evolution of an ant-plant mutualism: Comparative morphometrics of workers of two closely related plant-ants, petalomyrmex phylax and aphomomyrmex afer (formicinae). 46, 171-178. 
Meyer, C.P., Paulay, G., 2005. DNA barcoding: Error rates based on comprehensive sampling. Public Library of Science Biology 3, 2229-2238.

Meyers, M.J., Meyer, C.P., Resh, C.H., 2000. Neritid and thiarid gastropods from french polynesia streams: How reproduction (sexual, parthenogenic) and dispersal (active, passive) affect population structure. Freshwater Biology 44, 535545.

Minelli, A., 1993. Biological systematics: The state of the art. Chapman \& Hall, London.

Mishler, B.D., Theriot, E.C., 2000a. A critique from the mishler and theriot phylogentic species concept perspective: Monophyly, apomorphy, and phylogentic species concepts. In: Wheeler, Q.D., Meier, R. (Eds.), Species concpets and phylogenetic theory. Columbia University Press, New York.

Mishler, B.D., Theriot, E.D., 2000b. The phylogenetic species concept (sensu mishler and theriot): Monophyly, apomorphy, and phylogentic species concepts. In: Wheeler, Q.D., Meier, R. (Eds.), Species concepts and phylogenetic theory. Columbia Univeristy Press, New York.

Morehead, S.A., Seger, J., Jr., D.H.F., Brown, B.V., 2001. Evidence for a cryptic species complex in the ant parasitoid apocephalus paraponerae (diptera: Phoridae). Evolutionary Ecology Research 3, 273-284.

Moritz, C., Cicero, C., 2004. DNA barcoding: Promises and pitfalls. Public Library of Science Biology, pp. 1529-1531.

Nielsen, R., Matz, M., 2006. Statistical approaches for DNA barcoding. Systematic Biology 55, 162-169.

O'Corry-Crowe, G.M., Suydam, R.S., Rosenberg, A., Frost, K.J., Dizon, A.E., 1997. Phylogeography, population structure and dispersal patterns of the beluga wale delphinapterus leucas in the western neartic revealed by mitochondrial DNA. Molecular Ecology 6, 955-970.

Paquin, P., Hedin, M., 2004. The power and perils of 'molecular taxonomy': A case study of eyeless and endangered cicurina (araneae: Dictynidae) from texas caves. Molecular Ecology 13, 3239-3255.

Patterson, J.S., Schofield, C.J., Dujardin, J.P., Miles, M.A., 2001. Population morphometric analysis of the tropicopolitan bug triatoma rubrofasciata and relationships with old world species of triatima: Evidence of new world ancestry. Medicak and Vetinary Entomology 15, 443-451. 
Pole, M., 1994. The new zealand flora-entirely long-distance dispersal? Journal of Biogeography 21, 625-635.

Quicke, D.L.J., 1997. Priniciples and techniques of contemporary taxonomy. Blackie Academic and Professional, London.

Reid, W.V., 1992. How many species will there be? In: T C Whitmore, J.S. (Ed.), Tropical deforestation and species extinction. Chapman \& Hall, London, New York, pp. 55-57.

Roderick, G.K., Gillespie, R.G., 1998. Speciation and phylogeography of hawaiian terrestrial arthropods. Molecular Ecology 7, 519-531.

Roy, M.S., Sponer, R., 2002. Evidence of a human-mediated invasion of the tropical western atlantic by the 'world's most common brittlestar'. Proceedings of the Royal Society of London: Biology 269, 1017-1023.

Ruse, M., 1992. Biological species: Natural kinds, individuals, or what? In: Ereshefsky, M. (Ed.), The units of evolution: Essays on the nature of species. Bradford, Cambridge.

Simpson, G.G., 1951. The species concept. Evolution 5, 285-298.

Smith, P.F., Kornfield, I., 2002. Phylogeography of lake malawi cichlids of the genus pseudotropheus: Significance of allopatric colour variation. Proceedings of the Royal Society of London: Biology 269, 2495-2502.

Smith, W.W., 1895. On the habits of new zealand ants. Transactions and Proceedings of the Royal Society of New Zealand 28, 468-479.

Spaak, P., Denk, A., Boersma, M., Weider, L.J., 2004. Spatial and temporal patterns of sexual reproduction in a hybrid daphnia species complex. Journal of Plankton Research 26, 625-635.

Stamos, D.N., 2003. The species problem: Biological species, ontogeny, and the metphysics of biology. Lexongton Books, Lanham.

Stewart, J.B., Beckenbach, A.T., 2004. Insect mitochondrial genomics: The complete mitochondrial genome sequence of the meadow spittlebug philaenus spumarius (hemiptera: Auchenorrhyncha: Cercopoidae). Genome 48, 46-54.

Stöckler, K., Daniel, I.L., Lockhart, P.J., 2002. New zealand kauri (agathis australis (d.Don) lindl., araucariaceae) survives oligocene drowning. Systematic Biology 51, 827-832. 
Taberlet, P., Fumagalli, L., Wust-Saucy, A.-G., Cosson, J.-F., 1998. Comparative phylogeogrpahy and postglacial colonization routes in europe. Molecular Ecology 7, 453-464.

Templeton, A.R., 1989. The meaning of species and speciation: A genetic perspective. In: Otte, D., Endler, J.A. (Eds.), Speciation and its consequences. Sinauer Associates, Sunderland.

Templeton, A.R., Routman, E., Phillips, C.A., 1995. Separating population structure from population history: A cladistic analysis of the geographical distribution of mitochondrial DNA haplotypes in the tiger salamander, ambystoma tigrinurn. Genetics 140, 767-782.

Trewick, S.A., 2000. Molecular evidence for dispersal rather than vicariance as the origin of flightless insect species on the chatham islands, new zealand. Journal of Biogeography 27, 1189-1200.

Trewick, S.A., Wallis, G.P., 2001. Bridging the "Beech-gap": New zealand invertebrate phylogeography implicates pleistocene glaciation and pliocene isolation. Evolution 55, 2170-2180.

Verheyen, E., Ruber, L., Snoeks, J., Meyer, A., 1996. Mitochondrial phylogeography of rock-dwelling cichlid fishes reveals evolutionary influence of historical lake level fluctuations of lake tanganyika, africa. Philosophical Transactions: Biological Sciences 351, 797-805.

Vogler, A.P., Desalle, R., 1994. Diagnosing units of conservation management. Conservation Biology 8, 356-363.

Wallace, A.R., 1860. On the zoological geography of the Malay archipelago. the Linnean Society of London, Zoology 4, 172-184.

Wang, X.-H., Lester, P.J., 2004. A preliminary study of the usefulness of morphometric tools for splitting the monomorium antarctiucm (smith) complex (hymenoptera: Formicidae), new zealand's most common native ants. New Zealand Entomologist 27, 103-108.

Ward, D.F., 2005. Changes to the classification of ants (hymenoptera: Formicidae). The Weta: News Bulletin of the Entomological Society of New Zealand 30, 16-18.

Wardle, P., 1988. Effects of glacial climates on floristic distribution in new zealand 1. A review of the evidence. New Zealand Journal of Botany 26, 541-555. 
Wheeler, Q.D., Platnick, N.I., 2000. The phylogenetic species concept (sensu wheeler and platnick). In: Wheeler, Q.D., Meier, R. (Eds.), Species concepts and phylogenetic theory. Columbia University Press, New York.

Wheeler, W.M., 1936. Ants from the society, austral tuamotu and mangareva islands. Bernice P. Bishop Museum - Occasional Papers 12, 1-17.

Wiemers, M., Fiedler, K., 2007. Does the DNA barcoding gap exist? - a case study in blue butterflies (lepidoptera: Lycaenidae). Frontiers in Zoology 4.

Wiley, E.O., Mayden, R.L., 2000. The evolutionary species concept. In: Wheeler, Q.D., Meier, R. (Eds.), Species concepts and phylogentic theory: A debate. Columbia University Press, New York.

Willett, R., 1950. The new zealand pleistocene snow line, climatic conditions, and suggested biological effects. New Zealand Journal of Science and Technology $32,18-48$.

Wishart, M.J., Hughes, J.M., 2003. Genetic population structure of the netwinged midge, elporia barnardi (diptera: Blephariceridae) in streams of the southwestern cape, south africa: Implications for dispersal. Freshwater Biology 48, 28-38.

Wright, S., 1943. Isolation by distane. Genetics 38, 114-138.

Zelditch, M.L., Swiderski, D.L., SHeets, H.D., Fink, W.L., 2004. Geometric morphometrics for biologists: A primer. Elsevier, San Diego

London. 


\section{Chapter Two}

Searching for Species within Complexes: A Molecular and Morphological study of the New Zealand Ant Complex Monomorium antarcticum (Fr. Smith) (Hymenoptera :

Formicidae). 


\begin{abstract}
The native New Zealand ant complex Monomorium antarcticum was studied using a $627 \mathrm{bp}$ length of the COI region of mitochondrial DNA, traditional morphological and morphometric techniques. Evidence was found for at least three species within the complex using both molecular and morphological data. However, the results were not in concordance with DNA limits for species proposed in other work with other species, including ants. It seems all evidence supporting a new species must be assessed on its own merits and that conclusions from other work can only be transferred between taxa with care.
\end{abstract}

\title{
Key Words
}

Monomorium antarcticum, species limits, DNA barcoding, diagnosing species, mitochondrial DNA (mtDNA) 


\section{Introduction}

Cryptic species are species that cannot be separated easily or reliably using morphology alone (Bastrop et al., 1998; Blair, 1960; Mayr, 1942). Cryptic species are not necessarily closely related, however, in a species complex the species are not only hard to separate morphologically but generally thought to be closely related (Collins and Paskewitz, 1996). A classic example of a species complex is the malaria mosquito Anopheles gambiae Giles (Diptera: Culicidae). Due to human importance this complex has been studied since the 1960's and is one of the earliest recognised (Coetzee et al., 2000). The species within the A. gambinae complex are thought to be distinguishable only by their behaviour and molecular evidence (Coetzee et al., 2000; Collins and Hill, 2005).

Assuming that closely related species are recently diverged then sibling species should show a minimum amount of change - morphological, genetic and behavioural - from each other (Ayala et al., 1974). That makes species complexes an ideal study group (Panhuis et al., 2001) for trying to answer questions around speciation.

What degree of differentiation must there be between two organisms for them to be defined as different species? This question is of constant interest to evolutionary biologists (Dobzhansky, 1940; Loeb, 1937; Nei, 1971; Tattersall, 1992) and one way to investigate it is to study recently diverged species.

If the organisms within a complex seem to be morphologically identical or the morphology is too variable or complex such as to make an identification using morphology impractical then DNA is a potential tool to employ. Molecular data in species problems provide a layer of resolution beyond that of morphological structures. The change to a sequence of DNA often does not change any vital function, or the amino acid sequence itself (Komar, 2006). Consequently, changes can accumulate through time potentially differentiating apparently morphologically identical organisms. It must be noted that there is an argument that those 'silent' changes may have little bearing or relation to the mutations that drive speciation (Hafner et al., 1987) but that is another issue and is not discussed here. Molecular data has proved valuable in a number of cases where morphology was not sufficient to delineate a complex (Bastrop et al., 1998; Hebert et al., 2004; Morehead et al., 
2001). The Cytochrome Oxidase One (COI) region of the mitochondrial genome has proved a popular molecular marker in taxonomic studies when dealing with complexes or otherwise. The region possesses enough sequence divergence in most animals for the COI region to be an effective molecular tool (Hebert et al., 2003b) and sections of is sequence are conserved enough to allow the same primers to be used across a range of taxa (Hebert et al., 2003a; Kocher et al., 1989; Sorenson et al., 1999). The popularity also causes somewhat of a snowball effect, in that the more studies that use COI the more future studies will use them so as to allow comparisons between studies.

The use of DNA as a tool in defining species does have detractors. The arguments are primarily focussed on when a short (about 500 base pair) sequence of DNA such as a fragment of COI, often referred to as a 'barcode' (Hebert et al., 2003a) is used in isolation from morphological characters or further DNA sequences to identify new species. Some arguments are that the 'barcoding gap', the gap between intra and inter specific genetic variation, does not exist if comprehensive sampling is undertaken (Meyer and Paulay, 2005; Wiemers and Fiedler, 2007). The $\mathrm{COI}$ region is criticised for its conserved nature in some organisms -in that is does not evolve fast enough- ironically one of the features that made it a popular choice for barcoding studies (Hajibabaei et al., 2007). Others note the problems with the application of a standard percent DNA sequence difference between samples to predict species boundaries (Cognato, 2006). Many note the perils of using DNA in isolation from morphology (Moritz and Cicero, 2004; Quicke, 2004; Will et al., 2005).

Species complexes are found throughout the biological world and are very common in insects, due probably in part to the sheer number of insect species and the relatively low taxonomic knowledge. Species complexes have also been found relatively often in the well studied insect orders (Collins and Paskewitz, 1996) compared to other more conspicuous flora and fauna. Hence there tend to be regular discoveries of new species and rearrangement of existing ones within insects. Within Australia and New Zealand the Monomorium genus of ants has proved a taxonomic problem, with some conflict over how many species there are within it (Anderson, 2007; Bolton et al., 2006; Heterick, 2001) and the number of complexes within the genus (Anderson, 2007). In New Zealand there are considerably fewer ant species 
than in Australia. However there is only one recognized Monomorium complex, Monomorium antarcticum (Fr. Smith).

The Monomorium antarcticum complex is a group of relatively unremarkable ants, thought to be the most common native ant in New Zealand (Brown, 1958). It ranges in size from three to five millimetres in length, it exhibits a range of colours from jet black to a vivid orange (Brown, 1958), it is a generalist feeder, it is a likely seed collector (Don, 2007) but also tending homopterans (Don, 2007; Lester et al., 2008; Smith, 1895). They are often found nesting in very close proximity -under the same rock- as another nest of the same or a different species such as Monomorium smithii Forel or Huberia striata (Fr. Smith) (Lester et al., 2008). They are quite aggressive, ants actively attacking intruders using their stings, the venom of which, differing chemically amongst morphologically distinct nests and is cited as evidence for a complex (Don and Jones, 1993; Jones et al., 1986). In addition to the venom there is clear evidence for a complex in the size range of specimens and the morphological features exhibited (Brown, 1958), morphometric work also points at a complex (Wang and Lester, 2004). This paper investigates the complex as a whole using traditional morphological, morphometric and molecular data in the form of a mitochondrial gene fragment of the $\mathrm{COI}$ region. The aim of this work is to attempt to define boundaries of the species within the complex using the three techniques mentioned above.

\section{Methods}

\subsection{Collection of Samples}

The majority of samples were collected during the summer (NovemberFebruary) of 2006-2007. Samples were collected by in the field from nest sites and when possible queens, eggs and winged males were collected. Nests were mainly situated under rocks and once disturbed as many as ants as possible were collected via an aspirator and then decanted into a small plastic container with walls coated in Fluon $^{\text {tm }}$ (DuPont,Wilmington, DE) to prevent escape. From this container the workers, queens and eggs were transferred directly into a vial containing $70 \%$ 
ethanol. A small number of samples were not collected from an actual nest but the surrounds of a nest.

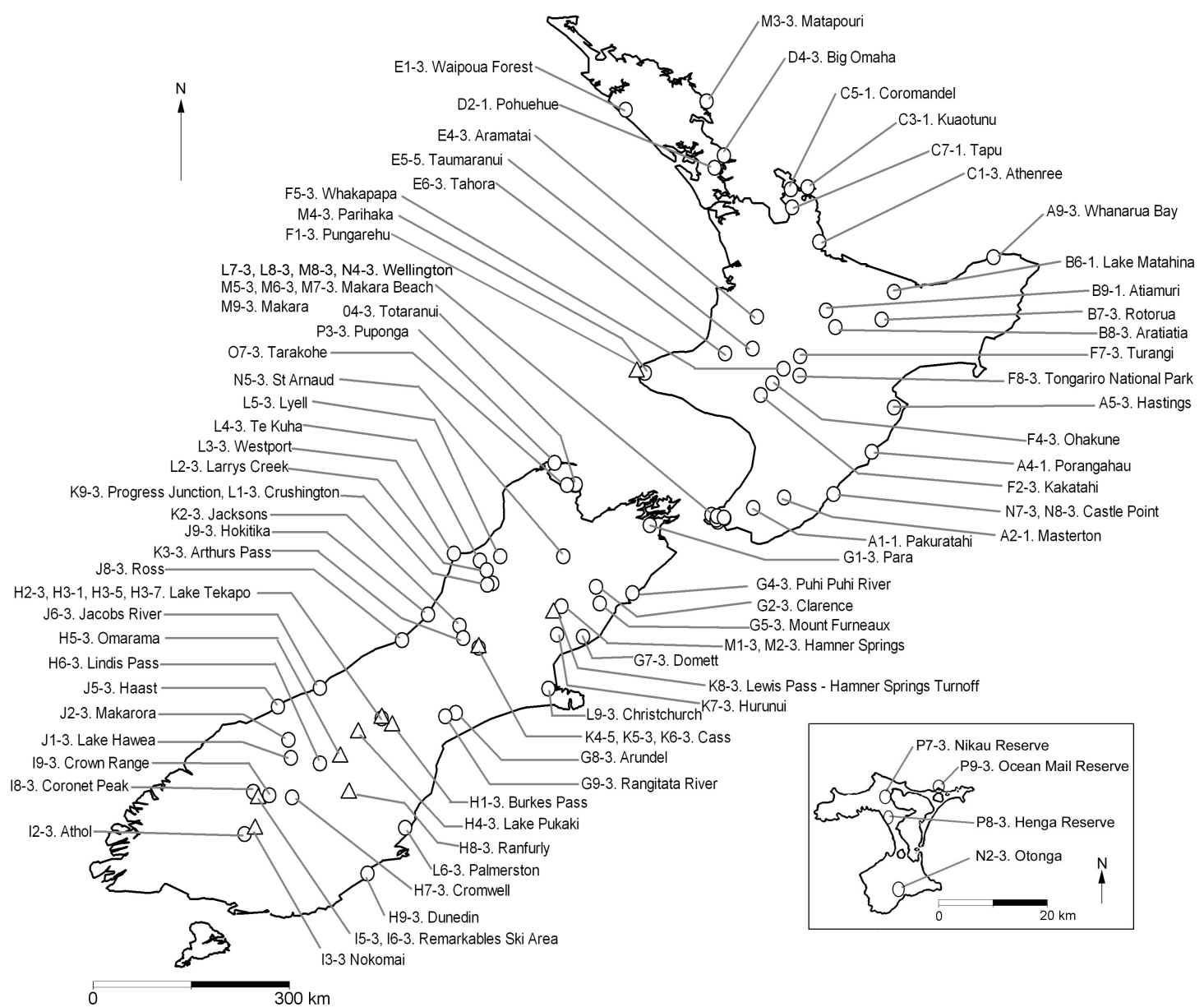

Figure 1. Map of samples. The circular points are the M. antarcticum samples and the triangles the $M$. smithii samples. Inset is the samples from Chatham Islands. The alphanumeric code (e.g. G1) refers to the sample site, and the following number refers to the extraction number from that site, note that some sites had more than one nest. Note that the Chatham Island is not to scale in terms of distance or placement relative to mainland New Zealand.

Additional samples were obtained from the Chatham Islands by Phil Sirvid (Museum of New Zealand, Te Papa) and Kevin Burns (Victoria University of Wellington) and from the Nelson, Marlborough region thanks to the Department of Conservation (DOC). The samples obtained from DOC differ from the bulk of the samples in that they were collected using baits. A vial containing bait was left out then recovered some time later (the exact time the bait was left is unknown), in some cases multiple vials were collated into one sample, but it was been noted when that occurred and those samples were not included in the morphological section.

Nevertheless it is likely that a sample from one single baited vial would contain the workers from only one nest as $M$. antarcticum nests have been observed in laboratory studies being very protective of food sources (Sagata, 2007). In total 110 
samples of $M$. antarcticum were obtained, and 14 samples of $M$. smithii were also collected for use in comparative analysis. The sites of the samples used in the molecular and morphology analysis can be seen in figure one.

\subsection{DNA Extraction, Amplification and Sequencing.}

DNA was extracted from a whole ant using the Chelex ${ }^{\circledR}$ method (Walsh et al., 1991), in some cases a leg of a queen was used so as not destroy the sample. The DNA was amplified using the Polymerase Chain Reaction (PCR) (Mullis et al., 1986), using the general invertebrate primers (L-COI-1490 and H-COII-2198) (Folmer et al., 1994) were used. A $25 \mu \mathrm{L}$ PCR mix consisted of; $1 \mu \mathrm{L}$ of DNA template, $1 \mu \mathrm{L}$ of each primer at $10 \mu \mathrm{M}, 1 \mu \mathrm{L}$ of BSA at $10 \mathrm{mg} / \mu \mathrm{L}, 200 \mu \mathrm{M}$ of each $\mathrm{dNTP}, 2.5 \mu \mathrm{L}$ of $10 \mathrm{x} \mathrm{NH} 4$ reaction buffer $\left(160 \mathrm{mM}\left(\mathrm{NH}_{4}\right)_{2} \mathrm{SO}_{4}, 670 \mathrm{mM}\right.$ Tris-HCI (pH8.8 at $25^{\circ} \mathrm{C}$ ), $0.1 \%$ Tween-20) (Bioline), $0.75 \mu \mathrm{L}$ of $50 \mathrm{mM} \mathrm{MgCl} 2$ (Bioline) and 1 unit of BioTaq DNA Polymerase (Bioline). Amplification of target DNA was conducted on an Eppendorf Mastercycler® ep gradient thermal cycler, using the following conditions: denaturation at $94^{\circ} \mathrm{C}$ for $2 \mathrm{~min}, 30$ cycles of $20 \mathrm{sec}$ at $94^{\circ} \mathrm{C}, 30$ sec at 40 (annealing) and $1 \mathrm{~min}$ at $72^{\circ} \mathrm{C}$, followed by extension at $72^{\circ} \mathrm{C}$ for $5 \mathrm{~min}$. The PCR products were purified using ExoSapIt (USB) and then directly sequenced using BigDye ${ }^{\mathrm{TM}}$ Terminator v3.1 and analysed on an ABI 3730 Capillary Sequencer (Applied BioSystems). Two sequences used in the molecular analysis, 'M. smithii. Waimarama' and 'M. destructor (accession number DQ353305), were not sequenced during this work but from previous yet unpublished data (Lester et al) and from GenBank $^{\circledR}$ respectively. In some cases an individual site had multiple nest or forms and several extractions were made from different individuals (the number after the alphanumeric code denotes a different individual was used), hence some sites such as H3 show up multiple times within the analysis.

\subsection{Molecular Data Analysis}

The sequenced DNA fragments were assessed in terms of quality using Finch $\mathrm{TV}^{\mathrm{tm}}$ a chromatogram trace viewer. Sequences of good quality were added to a MEGA $4^{\mathrm{tm}}$ (Tamura et al., 2007) alignment file; if a base pair site was ambiguous a 
manual correction was made based on the chromatogram trace file. The sequences were aligned by eye and trimmed down to 627 base pairs each, to eliminate unreliable sequence at the extreme ends of the files. In total 79 sequences of $M$. antarcticum were included in the analysis and 15 of $M$. smithii.

Kimura Two Parameter (K2P) neighbour joining trees (Saitou and Nei, 1987) and maximum parsimony trees were created using MEGA $4{ }^{\mathrm{tm}}$ with a variety of bootstrap values. A sequence of $M$. destructor was included as an outgroup. A number of basic statistics of the clades were generated using a combination of MEGA4 ${ }^{\mathrm{tm}}$ and Origin 6.1 (OriginLab, 1991-2000), the interquartile range was calculated using the embedded feature in Origin 6.1, those same statistics were calculated between the clades using the within means of the clades. Barcode gap graphs between the groups were made by creating a K2P pairwise matrix between all of the samples within a clade against all of the samples of another clade in MEGA $4^{\mathrm{tm}}$. The proportion of pairwise comparisons from the clade or between the clades that fell within the predetermined percent distance bins ( $0.5 \%$ intervals) was plotted. Based on the barcode gap graphs, the molecular tree, and the other statistics the samples were assigned to one of nine clades, being A to $\mathrm{H}$ and smithii, with smithii composed solely of samples of $M$. smithii.

\subsection{Morphological Data}

Seventeen morphological characters were used to construct a morphological data matrix. They were in part intuitive characters such as colour and size and others were adapted from Heterick (2001). The character set used seventeen characters used with the states of the characters following each character. Of the characters below, five (in bold and underlined) were considered to be useful. Those not in bold or underlined were not considered useful or informative because of any one of a number of reasons including: there was variation of the character within an individual sample such as a few cases with the alitrunk colour, the character was variable between two genetically/morphologically very close samples yet the same character was consistent between two otherwise genetically/morphologically disparate samples, in other words the character was an outlier that clashed with the other molecular and morphological characters; the character proved ambiguous showing a degree of 
gradation between the extremes of the character and hence was difficult to apply with consistency.

1. Alitrunk colour, orange/brown [1], dark brown to black [2], pale brown/whitish [3], vivid/translucent orange [4].

2. Median clypeal margin, distinct teeth projections [1], very slightly rounded lumps [2].

3. Basal Tooth of Mandibles, enlarged compared to non-apical teeth [1], not enlarged compared to non-apical teeth [2].

4.Propodeal sculpting, Smooth [1], striae, faint micro-reticulation [2], distinct microreticulation [3].

5. Sculpting on waist (not including petiolar process), none [1], micro-reticulation [2]

6. Propodeal lobe size, more than half as 'tall' as distance to dorsal extremity of propodeum [1], less than half as 'tall' as distance to dorsal extremity of propodeum [2].

7. Propodeal lobe shape, rounded dorsal edge [1], upturned or pointed dorsal edge [2].

8. Metaplueral lobes, distinct flanges, longitudinally overlapping with propodeal lobes [1], smaller flanges, not overlapping with propodeal lobes [2].

9. Propodeal declivity, flattened [1], concave [2]

10. Propodeal dorsal nodes, rounded [1], pointed [2].

11. Postpetiolar keel, no anterior pointing projection, keel points down [1], distinct anterior pointing projection [2].

12. Antennae colour, antennae same colour as head and alitrunk [1], antennae different colour than head and alitrunk [2].

13. Promesonotal suture, Absent, may have pit at the midpoint where suture would be [1], vestigial, faintly visible as impression on carapace [2], present as visible or faintly visible ridge, can be seen best as 'lip' when view longitudinally [3] 14. Petiolar Process, slight projection [1], distinct projection away from petiole [2]. 15. Metanotal groove, shallow, wide, small rise from propodeum up to mesonotum [1], deep, large rise from propodeum up to mesonotum [2].

16. Dorsal Propodeal Spiracle, Present as faintly depressed pit midway between metanotal groove and declivitous face [1], absent or vestigial as faint longitudinal 'crease' [2]. 
17. Size, small $<3 \mathrm{~mm}[1]$, large $>3 \mathrm{~mm}[2]$. -Note this character was only used between the $\mathrm{H} 3$ dark brown sample and the $M$. smithii samples.

A matrix of the informative characters was made and a maximum parsimony tree was made from the morphological data in PAUP ${ }^{\mathrm{tm}} 4.0$ (Swofford, 1998). Bootstrap values were not applied to the tree as bootstrap values are unreliable when used with a small number of characters (O'Leary et al., 2003).

\subsection{Morphometric Data}

Morphometric measurements were to add to the molecular and traditional morphological data. As recommended from Wang and Lester (2004), two measurements were taken, the Weber's length; a measurement from the anterior margin of the pronotum to the posterior extremity of the metaplueral lobe, and the hind tibia length; being the maximum length of the hind tibia. Ten workers were measured (where possible) from every sample. Those measurements were then pooled into their respective molecular and morphological clades. Additionally four detailed samples of 100 workers were made from four molecular and morphologically different samples. The Weber's length and the hind tibia length and the ratio of the pooled and detailed samples were tested for coming from the same population using the Mann-Whitney test (Mann and Whitney, 1947) employing a normal approximation due to the large sample sizes except for when clades $\mathrm{C}$ and $\mathrm{E}$ were tested against each other, in those cases the rank sum for the variable was used. The molecular clade H/morphological clade H3DB was not included as it had too few individuals. The Mann-Whitney tests were all calculated using StatTools 1.1 (Palisade, 2005) embedded in Microsoft Excel. The null hypothesis was that the samples measured come from the same population in other words that neither distribution tested tends to yield smaller values than the other. 


\section{Results}

\subsection{General Sequence/PCR Results}

The PCR products were of good quality and aligned easily by eye, with no insertions or deletions. When translated into a protein sequence the result was coherent with no abnormal stop codons, this strongly suggests all sequences were Mitochondrial DNA (mtDNA) and not nuclear pseudogenes. All the sequences exhibited the Adenine-Thymine bias common in insects (Crozier and Crozier, 1993). The trimmed length of the sequences was 627 base pairs, with 151 variable sites, 112 parsimony informative sites, 36 singleton sites and nucleotide composition of 39.3 , 17.3, 30 and 13.3 percent for Thymine, Cytosine, Adenine and Guanine respectively.

\subsection{Molecular Groups}

Eight molecular clades were defined from the COI sequence data (Fig 2), the basic statistical features of each clade can be seen in figure 3. Two clades $-\mathrm{G}$ and $\mathrm{H}-$ were clearly distinct from all other clades with no overlap with any other group in the barcode gap graphs, see figure 4, the clade 'smithii' also showed good separation from the other groups, but this is to be expected as $M$. smithii has been described as a distinct species. The other five clades ranged in their degree of separation from other clades, all exhibiting some overlap of the within and between variation (Fig 4), as can be seen with clades A and B and clades B and F. Most groups showed a point of separation in the barcode gap graphs of around 3.8\%-3.9\% K2P distance, those that did not such as between clades F and H, F and G (Fig 4) is probably due to a small sample size. 


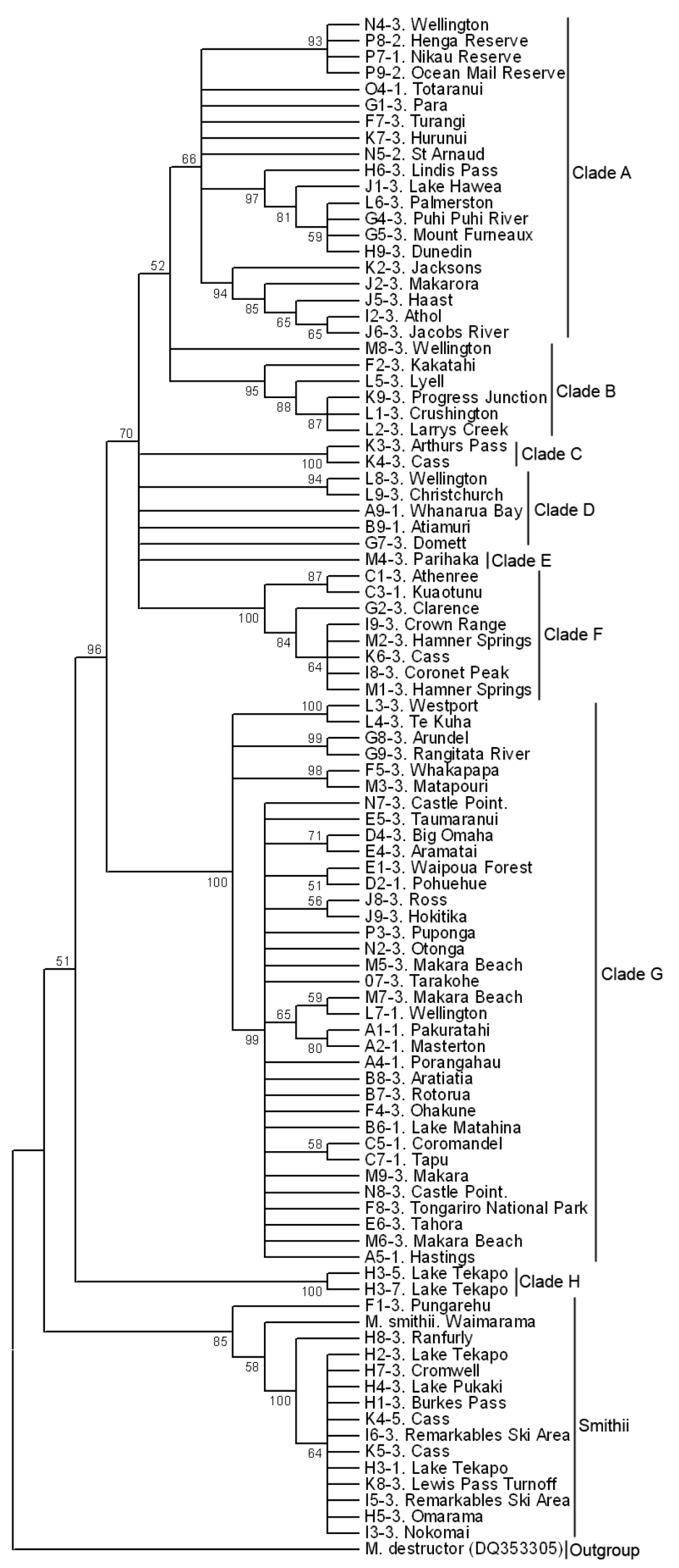

Figure 2. Neighbour joining tree from the molecular data. 5000 bootstrap replicates, nodes with less than fifty percent bootstrap support condensed. The eight molecular clades, plus smithii and the outgroup, are labelled. Note that two sequences (H3-5 and H3-7) of the H3 dark brown form were included so as to increase the sample size of the unique clade. 


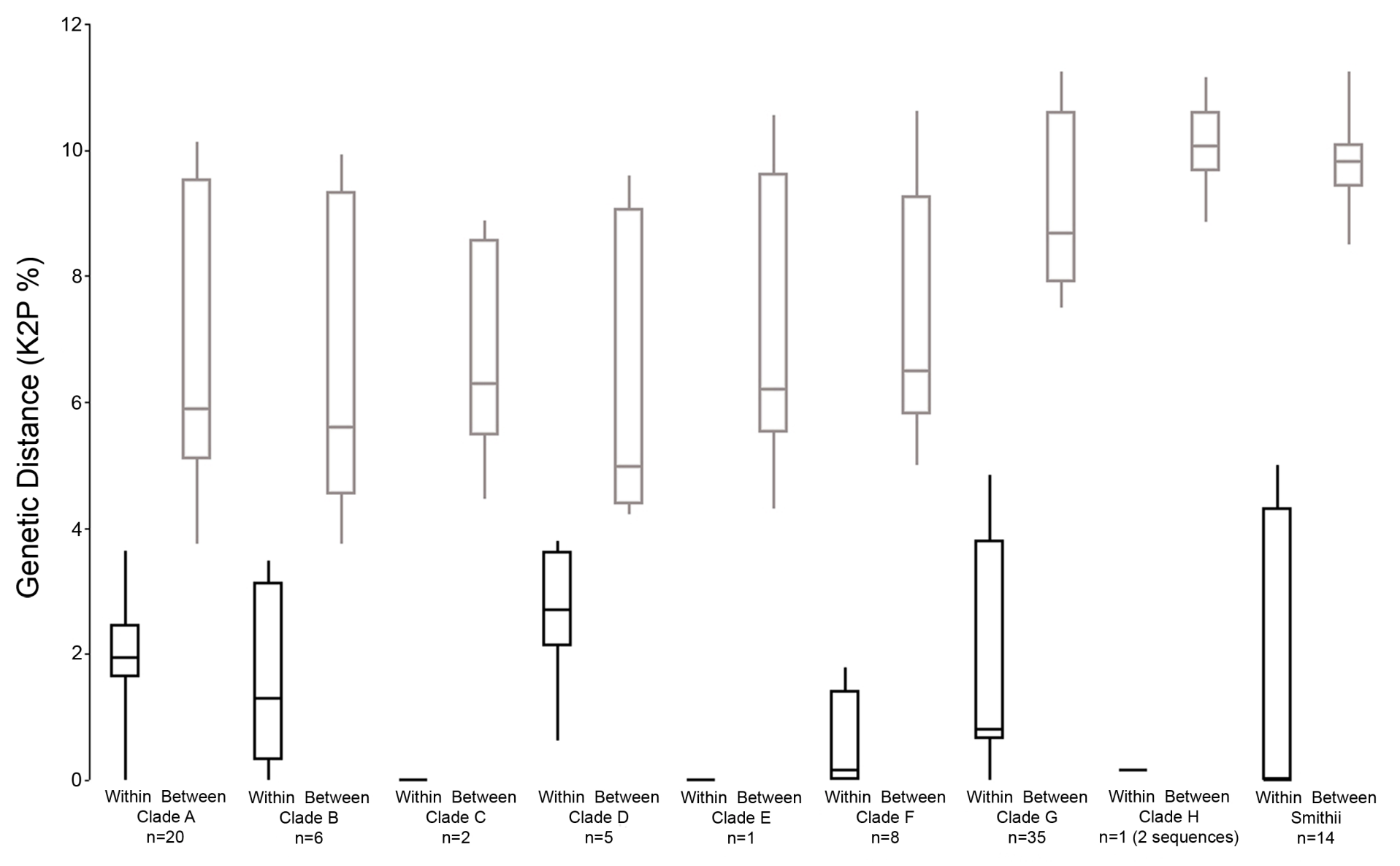

Figure 3. Box and Whisker plot of the general features of the molecular clades. The black box and whiskers are the summary of the intraclade K2P pairwise matrix and the grey the summary of the interclade pairwise matrix of the means of the clades. The whiskers show the range, the box the 25 and 75 percentile range and the mean. Note that smithii was not included in the between comparisons for the other clades and that some clades such as clade C, E and $\mathrm{H}$ have no within clade box as they have either only on sample, no variation amongst the samples, or very little variation respectively. 


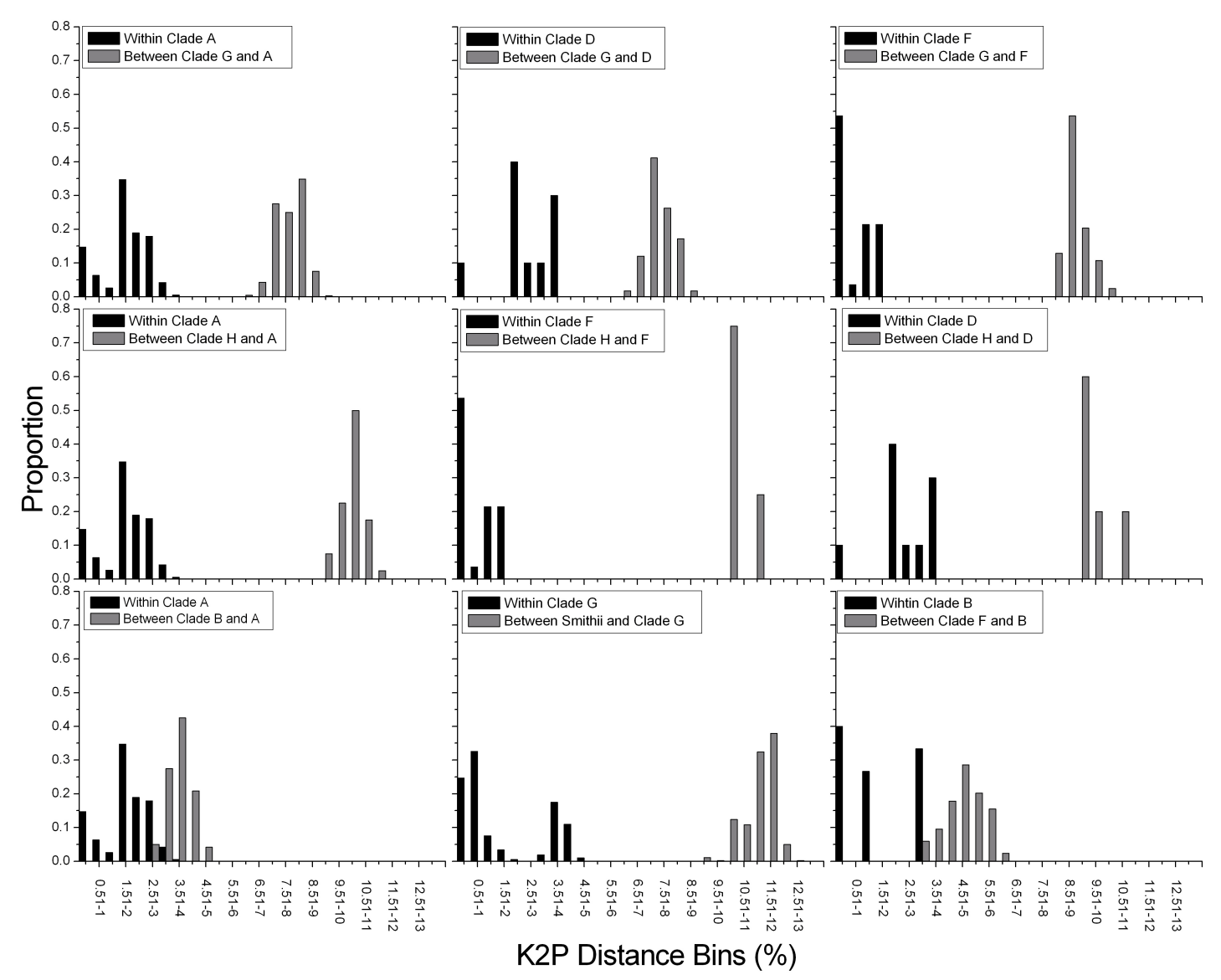

Figure 4. Barcode gap graphs of the molecular clades. The black columns are the intraclade variation, and the grey the interclade variation. The vertical axis is the proportion of pairwise comparisons that fell within the allotted K2P distance bins. All graphs are to the same scale. With nine clades there are a possible 72 graphs, only nine are included here, the first two rows of graphs are Clade $\mathrm{G}$ and $\mathrm{H}$, the two most distinct clades compared against various other clades, the bottom row of graphs from left are; an example of overlap of the within and between variation, the separation of smithii and an example of the effect of a poor sample size upon a barcode gap graph. Note that two sequences (H3-5 and H3-7) of the H3 dark brown form were included so as to increase the sample size of the clade.

\subsection{Morphological Groups}

Six clades were defined from the morphological data using five informative characters (Fig 5), those clades being; promesonotal suture present; vestigial suture present; no promesonotal suture shallow metanotal groove; no promesonotal suture deep metanotal groove; K3 K4 dark brown; H3 dark brown and smithii. The groups are referred to hereafter for brevity as; suture present, vestigial suture, no suture shallow groove, no suture deep groove, K3 K4 db, H3 db, and smithii respectively. They are the same as the molecular clades apart from the molecular clades D, E and F were condensed into one clade (no suture shallow groove) in the morphological clades. Some morphological characters states such as the presence, absence or 
vestigial state of the promesonotoal suture were quite difficult to apply consistently as the distinction between these characters was slight. The same can be said for the states of the metanotal groove; deep and shallow are somewhat subjective terms. The median clypeal margin character was far easier to apply with the two states being distinct and discrete.

\subsection{Morphometric Results}

The morphometric data were not as useful as the molecular or morphological data in delineating the samples. From the pooled measures only the smithii clade had a high probability of coming from a different population compared to the other individual molecular and morphological clades for the Weber's length, hind tibia length and the ratio of the two from the Mann-Whitney U tests (Table 1). Clade B showed a high probability of coming from a different population when compared against almost all (not clade $\mathrm{E}$ for the ratio) of the other individual molecular and all of morphological clades. All other clades showed mixed results (Table 1). Of the four detailed measures (100 individuals from four different samples) all four samples showed a high probability of coming from different populations than each other apart from C5 and I8 (Table 2). Figure 6 shows with the detailed sample of smithii (H8 on the graph) being distinct, all of the H8 plots not overlapping with any of the other samples. 


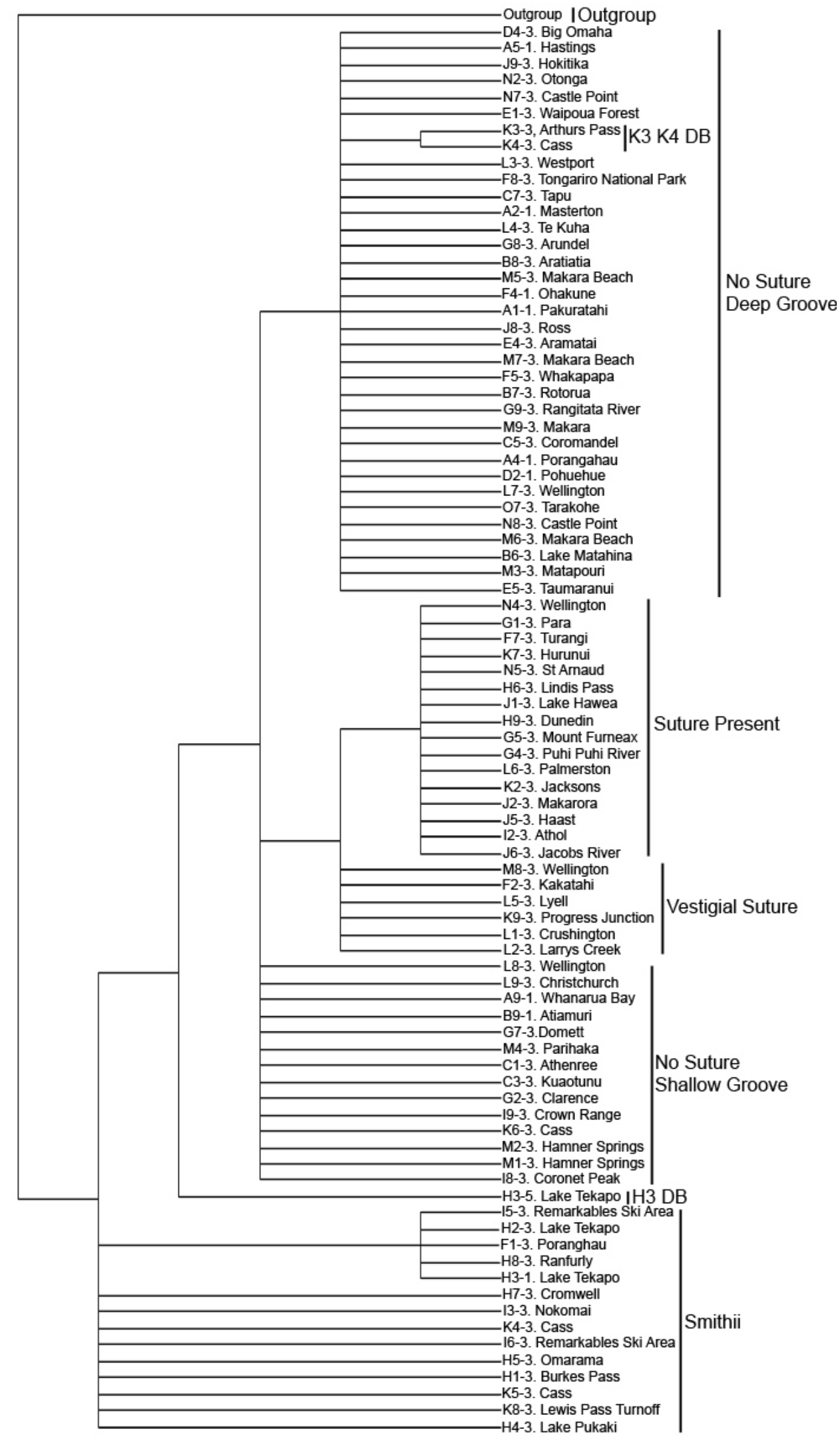

Figure 5. Maximum parsimony tree constructed from five morphological characters. Labelled are the six morphological clades plus smithii and a theoretical outgroup. Note that there are no bootstrap values are assigned to the nodes or branches as the bootstrap technique is unreliable with so few characters. 
Table 1. Mann-Whitney test results of the pooled samples. The test stat quoted is the $\mathrm{z}$-statistic, which is a normal approximation apart for between clade $\mathrm{C}$ and $\mathrm{E}$ (italicised) when the rank sum for the two variables is quoted. ' $W$ ' is the Weber's length, 'HTL' is the hind tibia length and ' $R$ ' is the ratio of those two measurements. The degrees of significance are $* \mathrm{p}<0.05$ and $* * \mathrm{p}<0.01$. Note that the molecular clades D,E and $\mathrm{F}$ were collated to form the morphological clade no suture shallow groove. The other molecular clades all correspond to a single morphological clade. The molecular clade $\mathrm{H}$ was not included as it had to few individuals.

Molecular Clade A
D
$\mathrm{F}$

G

A

B

C

'smithii'

$\mathrm{D}, \mathrm{E}, \mathrm{F}$

shallow groove)
$\mathrm{R}=-5.08^{* *}$

$\mathrm{W}=5.31^{* *}$

$\mathrm{HTL}=5.68^{* *}$

$\mathrm{R}=-0.36 \quad \mathrm{R}=2.12^{*}$

$W=-0.98 \quad W=-4.03^{* *}$

$H T L=-0.62 \quad H T L=-3.64^{* *}$

$\mathrm{R}=-1.54 \quad \mathrm{R}=3.64^{* *} \quad \mathrm{R}=-0.51$

$W=-5.44^{* *} \quad W=-7.80^{* *} \quad W=-2.84^{* *}$

$H T L=-4.31^{* *} \quad H T L=-7.58^{* *} \quad H T L=-2.30^{*}$

$\begin{array}{llll}\mathrm{R}=-2.36^{*} & \mathrm{R}=0.41 & \mathrm{R}=83 / 127 & \mathrm{R}=-2.30^{*} \\ \mathrm{~W}=1.21 & \mathrm{~W}=-2.13^{*} & \mathrm{~W}=133 / 77^{*} & \mathrm{~W}=3.63^{* *}\end{array}$

$\begin{array}{llll}W=1.21 & W=-2.13^{*} & W=133 / 77^{*} & W=3.63^{* *} \\ H T L=1.86 & H T L=-2.07^{*} & H T L=136.5 / 73.5^{*} & H T L=3.77^{* *}\end{array}$

$R=-2.67^{* *} \quad R=3.29^{* *} \quad R=-0.93 \quad R=-0.73 \quad R=1.89$

$W=2.13^{*} \quad W=-4.48^{* *} \quad W=2.48^{*} \quad W=6.61^{* *} \quad W=-0.49$

$H T L=2.43^{*} \quad H T L=-4.58^{* *} \quad H T L=2.30^{*} \quad H T L=6.19^{* *} \quad H T L=-1.23$

$R=1.42 \quad R=5.82^{* *} \quad R=0.20 \quad R=0.83 \quad R=2.78^{* *} \quad R=2.18^{*}$

$W=2.99^{* *} \quad W=-5.17^{* *} \quad W=2.43^{*} \quad W \quad W=7.80^{* *} \quad W=-0.53 \quad W=-0.07$

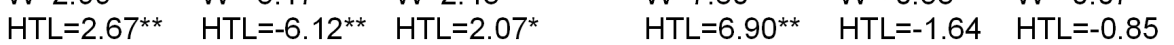

$R=-12.60^{* *} \quad R=-8.26^{* *} \quad R=-4.52^{* *}$

$W=14.64^{* *} \quad W=11.26^{* *} \quad W=5.35^{* *}$

$\mathrm{HTL}=14.50^{* *} \mathrm{HTL}=11.21^{* *} \mathrm{HTL}=5.36^{* *}$

$R=-9.03^{* *} \quad R=-3.67^{* *} \quad R=-10.39^{* *}$

$W=10.55^{* *} \quad W=5.35^{* *} \quad W=12.37^{* *} \quad W=15.19^{*}$

$W=10.55^{* *} \quad W=5.35^{* *} \quad W=12.37^{* *} \quad W=16.41^{* *}$

$H T L=10.56^{* *} \quad H T L=5.36^{* *} \quad H T L=12.35^{* *} \quad H T L=16.37^{* *}$

$\mathrm{R}=\mathrm{NA}$

$W=N A$

$\mathrm{HTL}=\mathrm{NA}$
$\mathrm{R}=\mathrm{NA}$

$H T L=N A \quad H T L=N A$
$\mathrm{R}=-2.63^{* *}$

$W=-3.30^{* *}$

$H T L=-2.64^{* *}$ 
Table 2. Mann-Whitney test results of the four detailed samples. The test stat quoted is the z-statistic, which is a normal approximation., ' $W$ ' is the Weber's length, 'HTL' is the hind tibia length and ' $\mathrm{R}$ ' is the ratio of those two measurements The degrees of significance are $* \mathrm{p}<0.05$ and $* * \mathrm{p}<0.01$. Note that $\mathrm{H} 8$ is a $M$. smithii sample.

\begin{tabular}{|c|c|c|c|}
\hline Sample & C5 & 18 & $\mathrm{H} 8$ \\
\hline C5 & & & \\
\hline 18 & $\begin{array}{l}R=-3.04^{* *} \\
W=-1.16 \\
H T L=-0.162\end{array}$ & & \\
\hline H8 & $\begin{array}{l}R=-11.87^{* \star} \\
W=12.28^{* \star} \\
H T L=12.30^{*-k}\end{array}$ & $\begin{array}{l}\mathrm{R}=11.83^{\star *} \\
W=-12.29^{* \star} \\
\mathrm{HTL}=-12.30^{\star *}\end{array}$ & \\
\hline L1 & $\begin{array}{l}R=-8.10^{* *} \\
W=4.50^{* *} \\
H T L=6.73^{* *}\end{array}$ & $\begin{array}{l}R=6.38^{\star *} \\
W=-5.87^{\star \star} \\
H T L=-7.25^{\star \star}\end{array}$ & $\begin{array}{l}R=10.08^{\star *} \\
W=-12.29^{* \star} \\
H T L=-12.30^{* *}\end{array}$ \\
\hline
\end{tabular}

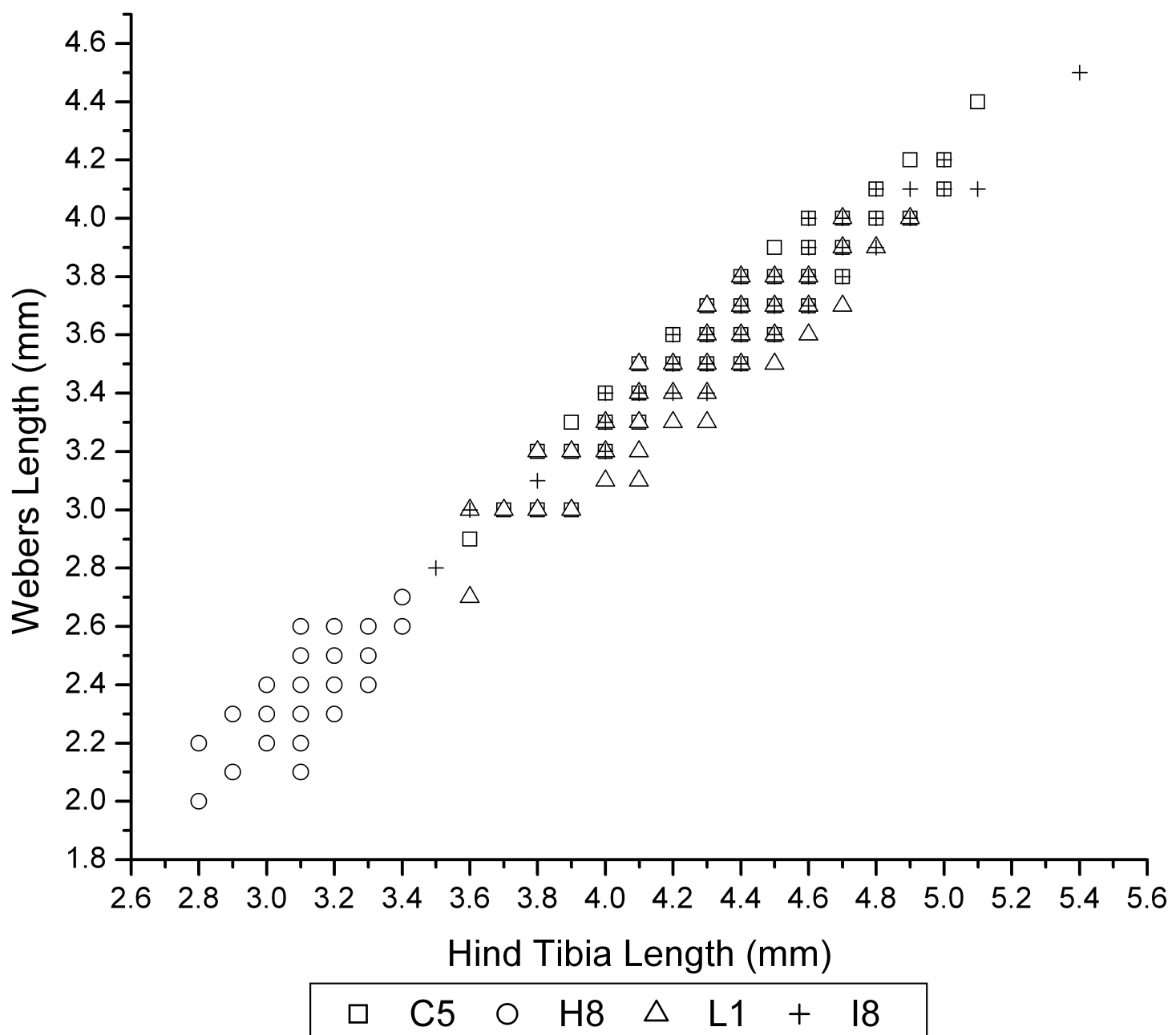

Figure 6. Scatter plot of the detailed morphometric measurements. C5, H8, L1 and I8. All come from different molecular and morphological clades. Note H8 is a sample of a smithii sample. 


\subsection{Integration of Molecular and Morphological Results}

With six clades defined from the morphological data and eight from the molecular data and considering small level of overlap in some of the molecular clades barcodes gap graphs, it seems prudent to be conservative and revert to the morphological clades. None of the morphological clades have major conflictions with the molecular framework, the congruence of the molecular and morphological trees can be seen in figure 7. Of these six clades it would seem responsible to suggest only two distinct 'species' be based on two clades from this work, these being clade H (H3 dark brown) and clade G (suture absent deep metanotal groove). Both clades show a clear, large separation from all other samples in the molecular data, the closest any one sample within no suture deep groove is to any other individual sample is $6.41 \% \mathrm{~K} 2 \mathrm{P}$ genetic distance whilst $\mathrm{H} 3 \mathrm{DB}$ is $9.1 \% \mathrm{~K} 2 \mathrm{P}$ away from any other individual sample. They both exhibit obvious, easily defined, morphological differences from the other samples. The other morphological clades have a degree of unresolved molecular data supporting them or the morphological characters that define them are difficult to apply consistently. Where the characters supporting them are not so easily defined and or recognisable, such as suture present and vestigial suture, the distinction between the promesonotal suture being present or vestigial is a delicate one. That leaves four clades that have some level of morphological and molecular differentiation but there is no evidence to support uniting those remaining four clades. 


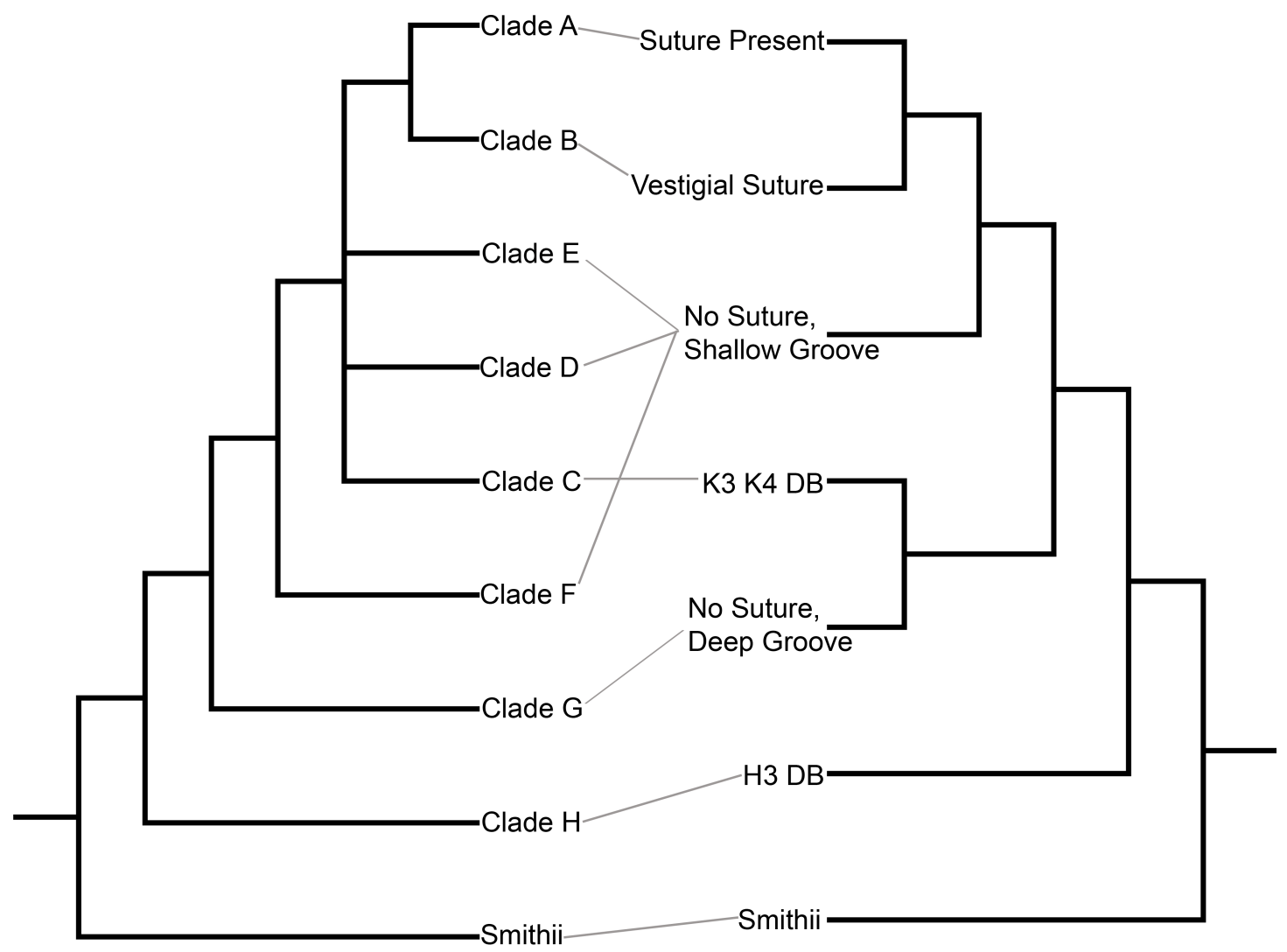

Figure 7. The congruence of the molecular and morphological trees. A simplified version of the molecular tree is on the left and the morphological tree on the right. The essential structure of the trees is unchanged from figures four and five.

\section{Discussion}

Two morphological clades (no suture, deep groove and H3 DB) showed sufficient molecular and morphological distinction from the other clades to be considered for recognition as distinct species. The remaining four clades showed some morphological and molecular differentiation from the other clades but not enough to be considered for recognition as species. Nonetheless amongst those four clades there must be at least one species, hence the complex encompasses at least three species. It is possible that the complex encompasses distinct species (Clades G and $\mathrm{H}$ ), truly morphologically cryptic forms (Clades D, E and F) and perhaps some incipient species (Clades A and B), those in the early stages of speciation. More data may have helped in the differentiation of the four clades not considered distinct species, both in the form of another mitochondrial gene and more morphological characters. An expanded sample of some of the underrepresented clades such as clades B, C and E may have given better resolution to the barcode gap graphs. It is 
possible that with more samples some of the barcode gaps may disappear (Wiemers and Fiedler, 2007). Similarly with more data for the morphometric analysis, a detailed sample - 100 measurements wherever possible- for every sample might provide another piece of reliable data to base the clades upon.

Whilst other molecular focussed work puts an emphasis upon the application of a sequence divergence threshold (samples with divergence values less than the threshold are grouped together) (Hebert et al., 2004; Hebert et al., 2003b; Smith et al., 2005) this work put more importance on the presence or absence of a barcode gap in addition to a degree of morphological differentiation. Though an approximate threshold can be drawn from the results of this work (3.8\%-3.9\%), if a threshold was defined and applied uniformly the resulting clades would be not as discrete as taking a more flexible approach. Other molecular taxonomic work on ants in Madagascar (Smith et al., 2005) used thresholds of 2 and 3\% and found that the molecular clades defined aligned well with the morphological clades, yet if that threshold was transferred to this sample set the result would be many more clades with smaller barcode gaps, if not overlap. Hence it seems imprudent to apply thresholds from other study groups regardless of their relatedness and agrees with other evidence against the concept of a universal threshold for insects (Cognto, 2006).

Molecular provided an excellent framework from which to search for morphological characters and without them the identification of useful morphological characters would have taken far longer. Nevertheless the morphological data was relied on to decide on the ultimate definitions of the clades. This was not an innate preference for morphological data over molecular, rather the morphological data were clearer and less convoluted in its groupings. Perhaps with more characters the morphological data would have exhibited the same degree of ambiguity as the molecular data, as the molecular data had 112 characters (parsimony informative sites) compared to the five used in the morphological analysis. More characters may have changed the results, different characters may have done the same. This work used some different characters than Brown (1958) in his revision of the New Zealand ant fauna. For instance he employed colour as a major character whilst this work suggests colour is not a good defining character. It is impossible to tell if the species boundaries in the two studies align, however the two studies do concur with the conclusion that there may only be two "good species" within the complex. 
Comprehensive sampling is necessary for any credible research and it is especially important in any taxonomic study of this kind where the aim is to delineate a complex, confidence in the range and resolution of samples is important (Bilgin et al., 2006; Morrison, 1996). The sample set used in this study is large in comparison to many other molecular taxonomic studies (Baker et al., 1995; Langor and Sperling, 1997; Medina et al., 1999; Sperling and Hickey, 1994). However, as no knowledge of the boundaries within the complex was known before sampling, there was no certain way to ensure a 'complete' sample set encompassing all forms of $M$. antarcticum. Additionally there are the practical constraints, both temporal and financial and securing an ideal sample set initially is always difficult. For example the lone sample that makes up the Clade $\mathrm{H}$ could be a sole sample for one of two reasons: Clade $\mathrm{H}$ is a rare form or it was only sampled once due to chance, or perhaps both and it is fortunate it was collected at all. Ideally a second round of sampling would take place to expand upon the under represented clades, knowing some of the morphological features to look for would help and hopefully make the second sampling more focussed than the first. Geographically the sample set was not ideal: no samples were obtained from Fiordland, Stewart Island or the far north and very few samples were obtained from the east coast of the North Island and Taranaki.

Collected incidentally, the samples of $M$. smithii proved valuable in the analysis especially of the molecular data. Being one of the closest related species to the complex, the smithii clade acted as an excellent outgroup and as a comparison for the other clades. As a settled species Smithii gave a good indication of the amount of genetic variation to expect within the clades.

The question of how much differentiation is required for a species to be separated from its closest relative does not have a clear answer. Applying a standard percentage of sequence divergence would not work uniformly as barcode gaps shift depending on the two clades being compared. Morphometrics was of little use, and as morphological characters are such a subjective quantity -there is no way to objectively compare and standardise morphological characters- it seems that each species has its own boundaries, and as such the evidence for a new species must be assessed on its own merits. 


\section{References}

Anderson, A.N., 2007. Ant diversity in arid Australia: A systematic overview. In: R Snelling, R., Fisher, B.L., Ward, P.S. (Eds.), Advances in ant systematics (Hymenoptera: Formicidae): Homage to e. O. Wilson - 50 years of contributions. American Entomological Institute, Gainesville, FL., pp. 19-51.

Ayala, F.J., Tracey, M.L., Hedgecock, D., Richmond, R.C., 1974. Genetic differentiation during the speciation process in drosophila. Evolution 28, 576-592.

Baker, A., Daugherty, C.H., Colbournes, R., McLennan, J.L., 1995. Flightless brown Kiwis of New Zealand possess extremely subdivided population structure and cryptic species like small mammals. Evolution 92, 8254-8258.

Bastrop, R., Jurss, K., Sturmbauer, C., 1998. Cryptic species in a marine polychaete and their independent introduction from North America to Europe. Molecular Biology and Evolution 15, 97-103.

Bilgin, R., Karatas, A., Çoraman, E., Pandurski, I., Papadatou, E., Morales, J.C., 2006. Molecular taxonomy and phylogeography of Miniopterus schreibersii (kuhl, 1817) (Chiroptera: Vespertilionidae), in the Eurasian transition. Biological Journal of the Linnean Society 87, 577-582.

Blair, W.F., 1960. Mating call as evidence of relations in the Hyla eximia group. The Southwestern Naturalist 5, 129-153.

Bolton, B., Alpert, G., Ward, P.S., Naskrecki, P., 2006. Bolton's catalogue of ants of the world, 1758-2005. Cd rom. Harvard University Press.

Brown, W.L.J., 1958. A review of the ants of New Zealand. Acta Hymenopterologica 1, 1-50.

Coetzee, M., Craig, M., Sueur, D.L., 2000. Distribution of African malaria mosquitoes belonging to the Anopheles gambiae complex. Parasitology Today 16, 74-77.

Cognato, A.I., 2006. Standard percent DNA sequence difference for insects does not predict species boundaries. Journal of Economic Entomology 99, 10371045.

Cognto, A.I., 2006. Standard percent DNA sequence difference for insects does not predict species boundaries. Journal of Economic Entomology 99, 1037-1045. 
Collins, F.H., Hill, C.A., 2005. The Anopheles gambiae genome. In: Sherman, I.W. (Ed.), Molecular approaches to malaria. ASM Press, Washington D.C.

Collins, F.H., Paskewitz, S.M., 1996. A review of the use of ribosomal DNA (RDNA) to differentiate among cryptic Anopheles species. Insect Molecular Biology $5,1-9$.

Crozier, R.H., Crozier, Y.C., 1993. The mitochondrial genome of the honeybee Apis melliferu: Complete sequence and genome organization. Genetics 133, 97-117.

Dobzhansky, T., 1940. Speciation as a stage in evolutionary divergence. The American Naturalist 74, 312-321.

Don, A.W., Jones, T.H., 1993. The stereochemistry of 3-butyl-5-(5-hexenyl)pyrrolizidine from population of Monomorium antarcticum (Smith) (Hymenoptera: Formicidae) and its possible role as a unique taxonomic character. New Zealand Entomologist 16, 45-48.

Don, W., 2007. Ants of New Zealand. Otago University Press, Dunedin.

Folmer, O., Black, M., Hoeh, W., Lutz, R., Vrijenhoek, R., 1994. DNA primers for amplification of mitochondrial cyrtochrome oxidase subunit I from diverse metazoan invertebrtes. Molecular Marine Biology and Biotechnology 3, 294-299.

Hafner, M.S., Hafner, J.C., Patton, J.L., Smith, M.F., 1987. Macrogeographic patterns of genetic differentiation in the pocket gopher Thomomys umbrinus. Systematic Zoology 36, 18-34.

Hajibabaei, M., Singer, G.A.C., Hebert, P.D., Hickey, D.A., 2007. DNA barcoding: How it complements taxonomy, molecular phylogenetics and population genetics. Trends in Genetics 23, 167-172.

Hebert, P.D.N., Cywinska, A., Ball, S.L., deWaard, J.R., 2003a. Biological identifications through DNA barcodes. Proceedings of the Royal Society of London: Biology 270, 313-321.

Hebert, P.D.N., Penton, E.H., Burns, J.M., Janzen, D.H., Hallwachs, W., 2004. Ten species in one: DNA barcoding reveals cryptic species in the Neotropical skipper butterfly Astrapes fulgerator. Proceedings of the National Academy of Sciences 101, 14812-14817.

Hebert, P.D.N., Ratnasingham, S., deWaard, J.R., 2003b. Barcoding animal life: Cytochrome c oxidase subunit 1 divergences among closely related species. Proceedings of the Royal Society of London: Biology 270, 96-99. 
Heterick, B.E., 2001. Revision of the Australian ants of the genus

Monomorium (Hymenoptera: Formicidae). Invertebrate Taxonomy 15, 353-459.

Jones, T.H., Highet, R.J., Don, A.W., Blum, M.S., 1986. Alkaloids of the ant

Chelaner antarcticus. Journal of Organic Chemistry 51, 2712.

Kocher, T.D., Thomas, W.K., Meyer, A., Edwards, S.V., Paabo, S., Villablanca, F.X., Wilson, A.C., 1989. Dynamics of mitochondrial DNA evolution in animals: Amplification and sequencing with conserved primers. Proceedings of the National Academy of Sciences 86, 6196-6200.

Komar, A.A., 2006. SNPs, silent but not invisible. Science 315, 466-467.

Langor, D.W., Sperling, F.A.H., 1997. Mitochondrial DNA sequence divergence in weevils of the Pissodes strobi species complex (Coleoptera: Curculionidae). Insect Molecular Biology 6, 255-265.

Lester, P.J., Dann, M.J., Ritchie, P.A., 2008. Coexistence and the use of habitat resources in a New Zealand sub-alpine ant community (Hymenoptera: Formicidae). Submitted Research. Victoria University of Wellington, Wellington.

Loeb, L., 1937. The biological basis of individuality. Science 86.

Mann, H.B., Whitney, D.R., 1947. On a test of whether one of two random variables is stochastically larger than the other. The Annals of Mathematical Statistics 18, 50-60.

Mayr, E., 1942. Systematics and the origin of species: From the viewpoint of a zoologist. Columbia University Press, New York.

Medina, M., Weil, E., Szmant, A.M., 1999. Examination of the Montastraea annularis species complex (Cnidaria: Scleractinia) using its and COI sequences. Marine Biotechnology 1, 87-97.

Meyer, C.P., Paulay, G., 2005. DNA barcoding: Error rates based on comprehensive sampling. Public Library of Science Biology 3, 2229-2238.

Morehead, S.A., Seger, J., Jr., D.H.F., Brown, B.V., 2001. Evidence for a cryptic species complex in the ant parasitoid Apocephalus paraponerae (Diptera: Phoridae). Evolutionary Ecology Research 3, 273-284.

Moritz, C., Cicero, C., 2004. DNA barcoding: Promises and pitfalls. Public Library of Science Biology, pp. 1529-1531.

Morrison, L.W., 1996. The ants (Hymenoptera: Formicidae) of Polynesia revisited: Species numbers and the importance of sampling intensity. Ecography 19, 73-84. 
Mullis, K., Faloona, F., Scharf, S., Saiki, R., Horn, G., Elrich, H., 1986. Specific enzymatic amplification of DNA in vitro: The polymerase chain reaction. Cold Spring Harbor Symposium on Quantitative Biology: Molecular Biology of Homo sapiens 51, 263-274.

Nei, M., 1971. Interspecific gene differences and evolutionary time estimated from electrophoretic data on protein identity. The American Naturalist 105, 385-398.

O'Leary, M.A., Gatesy, J., Novacek, M.J., 2003. Are the dental data really at odds with the molecular data? Morphological evidence for whale phylogeny (re)reexamined. Systematic Biology 52, 853-864.

OriginLab, 1991-2000. Origin 6.1. Origin Lab Corporation, Northhampton, Ma 01060, USA.

Palisade, 2005. Stattools: Statistics add-in for Microsoft® excel. Palisade Corporation, Newfield, NY.

Panhuis, T.M., Butlin, R., Zuk, M., Tregenza, T., 2001. Sexual selection and speciation. Trends in Ecology and Evolution 16, 364-371.

Quicke, D., 2004. The world of DNA barcoding and morphology - collision of synergism and what of the future. The Systemasist: Newsletter of the Systematics Association, pp. 8-12.

Sagata, K., 2007. The influence of propagule size on incipient colony establishment of invasive argentine ant, Linepithema humile Mayr (Hymenoptera: Formicidae). School Biology, Victoria University of Wellington, Wellington, p. 89.

Saitou, N., Nei, M., 1987. The neighbour-joining method: A new method for reconstructing phylogenetic trees. Molecular Biology and Evolution 4, 406-425.

Smith, M.A., Fisher, B.L., Hebert, P.D.N., 2005. DNA barcoding for effective biodiversity assessment of a hyperdiverse arthropod group: The ants of Madagascar. Philosophical Transactions of the Royal Society of Biology 360, 1825-1834.

Smith, W.W., 1895. On the habits of New Zealand ants. Transactions and Proceedings of the Royal Society of New Zealand 28, 468-479.

Sorenson, M.D., Ast, J.C., Dimcheff, D.E., Yuri, T., Mindell, D.P., 1999. Primers for a PCR-based approach to mitochondrial genome sequencing in birds and other vertebrates. Molecular Phylogenetics and Evolution 12, 105-114.

Sperling, F.A.H., Hickey, D.A., 1994. Mitochondrial DNA sequence variation in the spruce budworm species complex (Choristoneura: Lepidoptera). Molecular Biology and Evolution 11, 656-665. 
Swofford, D., 1998. Paup* 4.0. Sinauer Associates, Inc. Publishers, Sunderland, Massachusetts.

Tamura, K., Dudley, J., Nei, M., Kumar, S., 2007. Mega4: Molecular evolutionary genetics analysis (MEGA) software version 4.0. Molecular Biology and Evolution 24, 1596-1599.

Tattersall, I., 1992. Species concepts and species identification in human evolution. Journal of Human Evolution 22, 341-349.

Walsh, P.S., Metzger, D.A., Huguchi, R., 1991. Chelex ${ }^{\mathrm{r}} 100$ as a medium for simple extraction of DNA for PCR-based typing from forensic material. BioTechniques 10, 506-513.

Wang, X.-H., Lester, P.J., 2004. A preliminary study of the usefulness of morphometric tools for splitting the Monomorium antarcticum (Smith) complex (Hymenoptera: Formicidae), New Zealand's most common native ants. New Zealand Entomologist 27, 103-108.

Wiemers, M., Fiedler, K., 2007. Does the DNA barcoding gap exist? - A case study in blue butterflies (Lepidoptera: Lycaenidae). Frontiers in Zoology 4.

Will, K.W., Mishler, B.D., Wheeler, Q.D., 2005. The perils of DNA barcoding and the need for integrative taxonomy. Systematic Biology 54, 844-851. 


\section{Chapter 3}

The Genetic Population Structuring of the Native Ant Complex Monomorium antarcticum (Fr. Smith) (Hymenoptera :

Formicidae) within New Zealand based on Mitochondrial DNA: Insights into how the Genetic Structuring Relates to Geography and Dispersal Potential. 


\begin{abstract}
The native ant complex Monomorium antarcticum is New Zealand's most common and widespread group of ant species. The complex does not display any strong genetic population structuring concordant with current geography, based on the 627 bp mitochondrial DNA sequences of the cytochrome oxidase 1 region analysed in this study. Rather the genetic structuring of the population is attributed to the morphological differences within the population. It is proposed that the population of $M$. antarcticum contains cryptic species and was once divided and isolated to refugia which resulted in the genetic and morphological difference. A lack of strong genetic differentiation of populations is consistent with strong dispersal ability and a tolerance of a range of habitats. However, dispersal to the Chatham Islands approximately $700 \mathrm{kms}$ off mainland New Zealand - is thought to be human mediated due to identical haplotypes being collected on both Chatham Island and mainland New Zealand.
\end{abstract}

\title{
Key Words
}

Monomorium antarcticum, dispersal, population structuring, COI, historical refugia. 


\section{Introduction}

A species' dispersal capability can have a major effect on the genetic structuring of its population that organism belongs to. It is possible to make inferences about the potential genetic structuring of a population if good knowledge of dispersal and other factors affecting population structuring, such as reproduction, is available (Berven and Grudzien, 1900; Chepko-Sade and Halpin, 1987; Loveless and Hamrick, 1984). Alternatively good population genetic data can be used to make inferences about the dispersal patterns of a population (Avise, 1994; Cook et al., 2002; Hamrick et al., 1993; Kyle and Boulding, 2000). Furthermore, how the dispersal pattern relates to the genetic population structuring can provide interesting insights into the micro-evolutionary history of the population (Bohonak, 1999; Tero et al., 2003).

Identifying micro-evolutionary processes can help in the detection of potential sources of genetic variation. Identifying where the genetic variation of a population exists is an important factor in conservation programs of endangered species (Allendorf and Leary, 1988; Paetkau and Stroebeck, 1994), at the very least it can help prevent inbreeding (Frankham and Ralls, 1998). Knowledge of microevolutionary processes can assist in the identifying of important areas for conservation (Manel et al., 20003; Soares et al., 2008). Knowledge of a population's dispersal potential and the micro-evolutionary processes that shape it can help in the retention of biodiversity on a fine scale - the genetic variation within a population which is the basis for variation between species and the 'higher' levels of biodiversity.

Invertebrates display a large range of dispersal potential; some disperse in huge numbers over large distances whilst others tend to stay close to their hatching site throughout their life. Dispersal can have a significant affect on the genetic structuring of the population. For example an Australian species of Caddisfly (Trichoptera) has little genetic variation across large geographic scales which is consistent with widespread dispersal by the winged adults (Hughes et al., 1998). Contrastingly another species of Caddisfly from the Canary Islands displays levels of genetic variation comparable to a species with a much larger range suggesting the species has limited dispersal potential (Kelly et al., 2002). 
The ant Formica paralugubris of central Europe has very low gene flow between geographically distant nests and there is low genetic variation between close nests (Chapuisat et al., 1997; Liautard and Keller, 2001). However that example raises some of the complicating factors that can arise in the interpreting of genetic population structure in insects, especially social insects. Many nests in that study were a product of 'budding' -one queen leaving a nest with a few workers to form a new nest nearby - rather than the queen going on a nuptial flight, matings within the same nest were also detected. All genetic population structure studies of insects, regardless of reproductive strategy of the organisms in question, can be faced with the problem of cryptic species. Cryptic species - species that appear identical - can result in genetic variation that in a population structuring context would suggest poor dispersal capabilities or isolation currently or at some time in history (Gomez et al., 2002).

New Zealand has had a relatively active geological history with many upheavals such as the creation of the Southern Alps that run along the longitudinal centre of the South Island, several historical inundations of the land and the spread and retreat of glaciers (Cooper and Cooper, 1995; Emberson, 1995; Landis et al., 2008; Stöckler et al., 2002; Trewick and Wallis, 2001; Wardle, 1988; Willett, 1950). Consequently there are many examples of population structuring in a New Zealand context. The endemic mudfish (Neochanna diversus) displays cryptic species and population structuring consistent with it being isolated to disjunct 'islands' during Pliocene (2-6 million years ago) (Gleeson et al., 1999). The flightless brown Kiwi also displays a similar pattern of population structure as the mudfish but in that case the genetic variation is in part attributed to low dispersal power (Baker et al., 1995).

Monomorium antarcticum, the study organism of this work, displays many of the aforementioned features that can make studies of genetic population structuring difficult. Like many other ant species it can be polygynous (Don, 2007; Wang and Lester, 2004), in that the nest can have several queens. Their mating system is like that of other ants in that at a certain time - late summer in New Zealand (Smith, 1895 ) -newly emerged females (queens) and males will go on nuptial flights to find a mate. From there the queens will go on to found nests. These nuptial flight can result in sizable moving mating swarms with queens dropping out of the swarms along the way to establish nests (Smith, 1895). There is no record of the distance 
possible during such nuptial flights is known for M. antarcticum. However research on Solenopsis invicta the Fire Ant in North America, which is in the same tribe as $M$. antarcticum, shows that with no wind assistance a queen could travel $5.4 \mathrm{kms}$ and stay aloft for approximately 45 minutes (Vogt et al., 2000). There are records of $S$. invicta queens travelling 10km from the nest they emerged from (Holldobler and Wilson, 1990).

M. antarcticum can inhabit a wide range of habitats, (Brown, 1958; Don, 2007) both native and disturbed such as pasture and urban gardens. Although not known to be closely associated with humans such as in the case of many other ants, it may have the potential for human mediated dispersal dues to its commonness in urban situations (Don, 2007), their small size, and that during the mating period winged queens are occasionally found in unusual places (such as in clothing, personal observation) and in cars (Lester, personal correspondence 2008).

In this work we aim to quantify the genetic variation within the $M$. antarcticum complex and infer from that variation the genetic structuring of the population, the dispersal patterns of the complex and its micro-evolutionary history. To study the population structuring and the dispersal of M. antarcticum, mitochondrial DNA (mtDNA) is used due to its non-recombination during sexual reproduction. An individual mtDNA sequence is one of the finest scales of molecular data with every nucleotide difference between sequences indicating not only differentiation due to drift whilst reproductively isolated but also an element of time, in that the longer the lineages the sequences belong to have been isolated (or drifting apart) the more nucleotide differences there will between the sequences (Nei, 1971). This allows the effective barriers to dispersal and therefore gene flow to be recognised, in other words diagnosing some of important factors in micro-evolution (Bohonak, 1999; Slatkin, 1987) and macro-evolutionary processes (Avise et al., 1987). 


\section{Methods}

\subsection{Collection of Samples}

The majority of samples were collected during the summer (NovemberFebruary) of 2006-2007. Samples were collected in the field from nest sites and when possible queens, eggs and winged males were collected. Nests were mainly situated under rocks and once disturbed as many ants as possible were collected via an aspirator and then decanted into a small plastic container with walls coated in Fluon $^{\mathrm{tm}}$ (DuPont, Wilmington, DE) to prevent escape. From this container the workers, queens and eggs were transferred directly into a vial containing $70 \%$ ethanol. A small number of samples were not collected from an actual nest but the surrounds of a nest. The samples were labelled on collection with an alphanumeric site code. Additional samples were obtained from the Chatham Islands by Phil Sirvid (Museum of New Zealand, Te Papa) and Kevin Burns (Victoria University of Wellington) and from the Nelson, Marlborough region thanks to the Department of Conservation (DOC). The samples obtained from DOC differ from the bulk of the samples in that they were collected using baits. A vial containing bait was left out then recovered some time later (the exact time the bait was left is unknown), in some cases multiple vials were collated into one sample, but it was been noted when that occurred and those samples were not included in the morphological section, however it is likely that a sample from one single baited vial would contain the workers from only one nest. In total 110 samples of $M$. antarcticum were obtained, and 14 samples of Monomorium smithii were also collected for use in comparative analysis. The sites of the samples used in the molecular and morphology analysis can be seen in Figure one. 


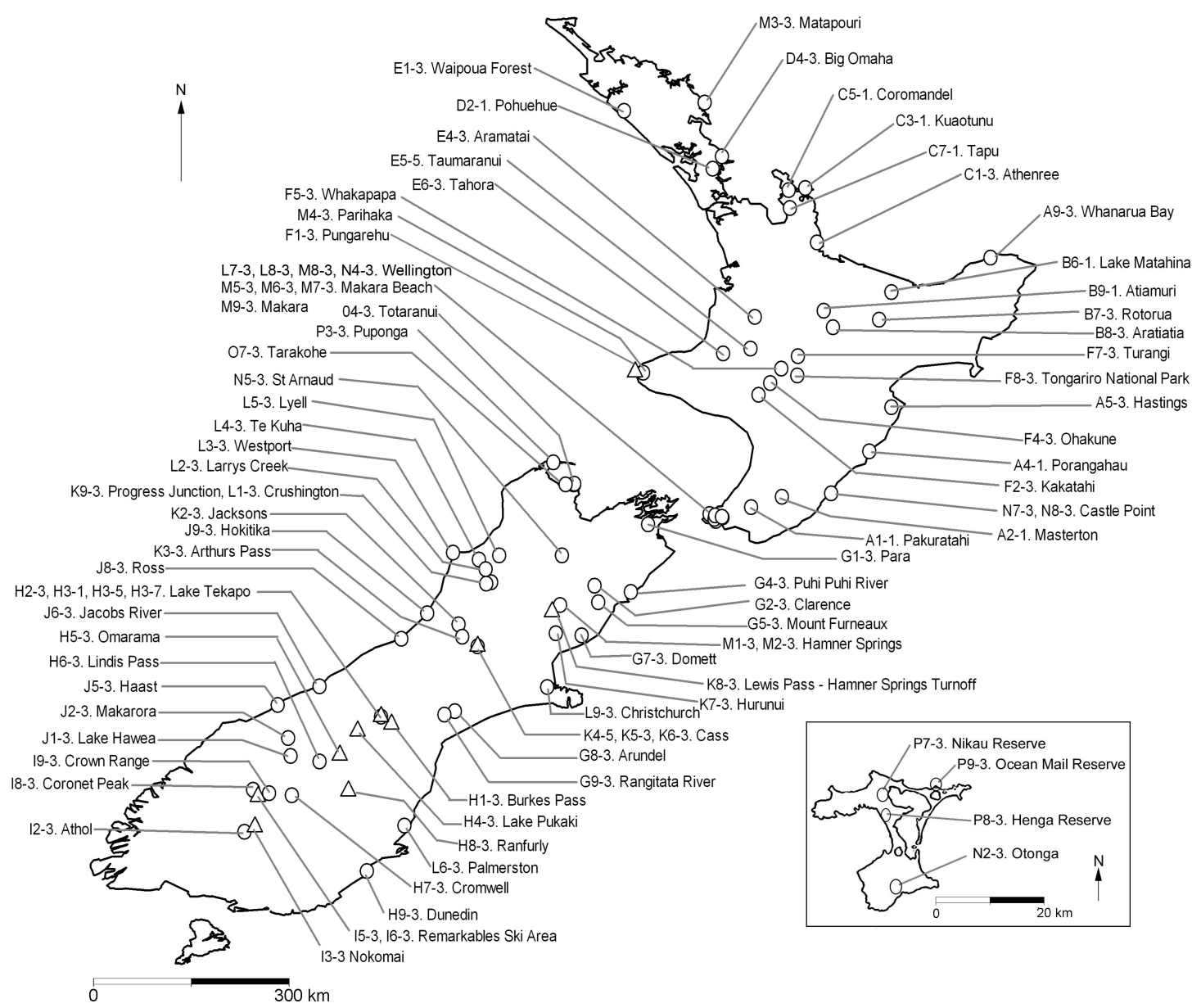

Figure 8. Map of samples. The circular points are the $M$. antarcticum samples and the triangles the $M$. smithii samples. Inset is the Chatham Islands. The alphanumeric code (e.g. G1) refers to the sample site, and the following number refers to the extraction number from that site, note that some sites had more than one nest. Note that the Chatham Island is not to scale in terms of distance or placement relative to mainland New Zealand.

\subsection{DNA Extraction, Amplification and Sequencing.}

DNA was extracted from a whole ant using the Chelex ${ }^{\circledR}$ method (Walsh et al., 1991), in some cases a leg of a queen was used so as not destroy the sample. The DNA was amplified using the Polymerase Chain Reaction (PCR) (Mullis et al., 1986), the general invertebrate primers (L-COI-1490 and H-COII-2198) (Folmer et al., 1994) were used. A $25 \mu \mathrm{L}$ PCR mix consisted of; $1 \mu \mathrm{L}$ of DNA template, $1 \mu \mathrm{L}$ of each primer at $10 \mu \mathrm{M}, 1 \mu \mathrm{L}$ of BSA at $10 \mathrm{mg} / \mu \mathrm{L}, 200 \mu \mathrm{M}$ of each $\mathrm{dNTP}, 2.5 \mu \mathrm{L}$ of $10 \mathrm{x} \mathrm{NH} 4$ reaction buffer $\left(160 \mathrm{mM}\left(\mathrm{NH}_{4}\right)_{2} \mathrm{SO}_{4}, 670 \mathrm{mM}\right.$ Tris-HCI $\left(\mathrm{pH} 8.8\right.$ at $\left.25^{\circ} \mathrm{C}\right)$, $0.1 \%$ Tween-20) (Bioline), $0.75 \mu \mathrm{L}$ of $50 \mathrm{mM} \mathrm{MgCl}_{2}$ (Bioline) and 1 unit of BioTaq DNA Polymerase (Bioline). Amplification of target DNA was conducted on an Eppendorf Mastercycler ${ }^{\circledR}$ ep gradient thermal cycler, using the following conditions: 
denaturation at $94^{\circ} \mathrm{C}$ for $2 \mathrm{~min}, 30$ cycles of $20 \mathrm{sec}$ at $94^{\circ} \mathrm{C}, 30 \mathrm{sec}$ at 40 (annealing) and $1 \mathrm{~min}$ sec at $72^{\circ} \mathrm{C}$, followed by extension at $72^{\circ} \mathrm{C}$ for $5 \mathrm{~min}$. The PCR products were purified using ExoSapIt (USB) and then directly sequenced using BigDye ${ }^{\mathrm{TM}}$ Terminator v3.1 and analysed on an ABI 3730 Capillary Sequencer (Applied BioSystems). Two sequences used in the molecular analysis, 'M. smithii Waimarama' and 'M. destructor (accession number DQ353305), were not sequenced during this work but from previous yet unpublished data (Lester P J, unpublished data) and from GenBank ${ }^{\circledR}$ respectively. In some cases an individual site had multiple nests or forms and several extractions were made from different individuals (the number after the alphanumeric code denotes a different individual was used), hence some sites such as H3 show up multiple times within the analysis.

\subsection{Molecular Data Analysis}

The PCR products were of good quality with no insertions or deletions. When translated into a protein sequence the result was coherent with no abnormal stop codons observed, this strongly suggests all sequences were Mitochondrial DNA (mtDNA) and not nuclear pseudogenes. All the sequences exhibited the AdenineThymine bias common in insects (Crozier and Crozier, 1993). The sequenced DNA fragments were assessed in terms of quality using Finch $\mathrm{TV}^{\mathrm{tm}}$ a chromatogram trace viewer. Sequences of good quality were added to a MEGA $4^{\mathrm{tm}}$ (Tamura et al., 2007) alignment file; if a base pair site was ambiguous a manual correction was made based on the chromatogram trace file. The sequences were aligned by eye and trimmed down to 627 base pairs each, to eliminate unreliable sequence at the extreme ends of the sequences. The dataset displayed 151 variable sites, 112 parsimony informative sites, 36 singleton sites and nucleotide composition of 39.3 , 17.3, 30 and 13.3 percent for Thymine, Cytosine, Adenine and Guanine respectively. In total 79 sequences of $M$. antarcticum were included in the analysis and 15 of $M$. smithii in addition to the sequence of $M$. destructor mentioned previously.

\subsection{Phylogeny Construction}

Model test 3.7 (Posada and Crandall, 1998) was implemented within $\mathrm{Mr}$ Model Test (Nylander, 2004) in conjunction with PAUP*4.0 (Swofford, 2002) to 
estimate the model of evolution that best fit the sequence data. The hierarchical likelihood-ratio tests (hRLT) selected the Tamura Nei model (Tamura and Nei, 1993) with gamma-distributed rate variation and proportion of invariable sites variation $(\operatorname{TrN}+\mathrm{I}+\mathrm{G}, \mathrm{I}=0.5957, \mathrm{G}=0.7987,-\operatorname{lnL}=3406.4309)$ as the most appropriate model of evolution.

Phylogenies were reconstructed by two methods using the parameters estimated in Model Test. The Neighbour-Joining (Saitou and Nei, 1987) method implemented in MEGA4 (Tamura et al., 2007) and the Bayesian method implemented in Mr Bayes (Ronquist and Huelsenbeck, 2003). The Bayesian analysis used six Metropolis-coupled Markov chain Monte Carlo chains, with two being 'heated' due to the relatively large sample size, as recommended in the Mr Bayes documentation. The chains started from a random tree and ran for 1 million generations, being sampled every hundred generations. The neighbour joining method implemented the parameters estimated in Model Test and employed 10000 bootstrap replicates. In cases where there was more than one sample exhibiting exactly the same sequence as another sample all but one of the samples were removed from the data set before analysis to prevent possible biasing in the phylogenies (Kruse and Sperling, 2001; Stuart and Parham, 2004).

\subsection{Morphological Data}

Seventeen morphological characters were used to construct a morphological data matrix. These were in part intuitive characters such as colour and size and others were adapted from Heterick (2001). The character set used seventeen characters used with the states of the characters following each character. Characters in bold and underlined were found to be useful and used further in the morphological analysis. 1. Alitrunk colour, orange/brown [1], dark brown to black [2], pale brown/whitish [3], vivid/translucent orange [4].

2. Median clypeal margin, distinct teeth projections [1], very slightly rounded lumps [2].

3. Basal Tooth of Mandibles, enlarged compared to non-apical teeth [1], not enlarged compared to non-apical teeth [2].

4. Propodeal sculpting, Smooth [1], striae, faint micro-reticulation [2], distinct micro-reticulation [3]. 
5. Sculpting on waist (not including petiolar process), none [1], micro-reticulation [2]

6. Propodeal lobe size, more than half as 'tall' as distance to dorsal extremity of propodeum [1], less than half as 'tall' as distance to dorsal extremity of propodeum [2].

7. Propodeal lobe shape, rounded dorsal edge [1], upturned or pointed dorsal edge [2].

8. Metaplueral lobes, distinct flanges, longitudinally overlapping with propodeal lobes [1], smaller flanges, not overlapping with propodeal lobes [2].

9. Propodeal declivity, flattened [1], concave [2]

10. Propodeal dorsal lumps, rounded [1], pointed [2].

11. Postpetiolar keel, no anterior pointing projection, keel points down [1], distinct anterior pointing projection [2].

12. Antennae colour, antennae same colour as head and alitrunk [1], antennae different colour than head and alitrunk [2].

13. Promesonotal suture, Absent, may have pit at the midpoint where suture would be [1], vestigial, faintly visible as impression on carapace [2], present as visible or faintly visible ridge, can be seen best as 'lip' when view longitudinally [3] 14. Petiolar Process, slight projection [1], distinct projection away from petiole [2]. 15. Metanotal groove, shallow, wide, small rise from propodeum up to mesonotum [1], deep, large rise from propodeum up to mesonotum [2].

16. Dorsal Propodeal Spiracle, Present as faintly depressed pit midway between metanotal groove and declivitous face [1], absent or vestigial as faint longitudinal 'crease' [2].

17. Size, small [1], large [2]. -Note this character was only used between the H3 dark brown sample and the $M$. smithii samples.

Ten characters (those not in bold or underlined) were not considered useful or informative because of any one of a number of reasons; there was variation of the character within an individual sample such as a few cases with the alitrunk colour, the character was variable between two genetically or morphologically very close samples yet the same character was consistent between two otherwise genetically/morphologically disparate samples, in other words the character was an outlier that clashed with the other molecular and morphological characters; the 
character proved ambiguous showing a degree of gradation between the extremes of the character and hence was difficult to apply with consistency.

A matrix of the informative characters was made and a maximum parsimony tree was made from the morphological data in PAUP ${ }^{\mathrm{tm}} 4.0$ (Swofford, 1998).

Bootstrap values were not applied to the tree as bootstrap values are unreliable when used with a small number of characters (O'Leary et al., 2003).

\subsection{Population Partitioning and Analysis of Molecular Variance}

For the population genetics analysis the sequences were partitioned into four different arrangements of possible populations. One based on the six morphological groups defined using the morphological data, a second based on the three major phylogeny branches, a third based on the North, South and Chatham Islands and a fourth based on the habitat the samples were collected from, either native forest, native grass/scrubland or disturbed areas/pasture. Those different arrangements of the samples into possible populations were then tested for amount of variance within and between the populations. This was done using the analysis of molecular variance (AMOVA) method implemented in Arlequin 3.1 (Excoffier and Schneider, 2005), additionally the Fixation index $\left(\mathrm{F}_{\mathrm{st}}\right)$ was also calculated in Arlequin 3.1 as a measure of the genetic isolation of the different population arrangements.

\subsection{Isolation by Distance}

The Isolation by distance model (Wright, 1943) was tested by plotting the pairwise straight line geographic distance in kilometres against the pairwise Kimuratwo-parameter (K2P) (Kimura, 1980) genetic distance. K2P values were used instead of pairwise $\mathrm{F}_{\mathrm{st}}$ values in this case as the $\mathrm{F}_{\mathrm{st}}$ assumes the populations are restricted to a small geographic range as in (Wishart and Hughes, 2003), whereas in this case the populations are spread over large ranges. The reduced major axis regression (RMA) (Sokal and Rohlf, 1981) and the association between the genetic and geographic distance was tested using Mantel's permutation test (Mantel, 1967), implemented by the Isolation By Distance Web Service (Jensen et al., 2005). 


\subsection{Geographical Spread of Samples}

A scatter plot of where the samples from the six morphological groups were collected was constructed to aid identifying geographical structuring of the population. Cook Strait, the water separating the North and South Island, an expanse of the South Pacific separating Chatham Island from mainland New Zealand, the Southern Alps that run down spine of the South Island and latitude were all considered as potential geographic boundaries to dispersal. Pairwise genetic (K2P) and geographic distance was plotted for the 'close' (defined as within $15 \mathrm{~km}$ of each other) samples. Also a simple column graph was constructed showing the geographic separation of all the identical haplotype pairs.

\section{Results}

\subsection{Phylogenies}

Both the Neighbour-Joining and Bayesian methods produced essentially the same phylogenies structurally (Fig 2). Some minor cosmetic differences we observed in term of situation of some samples such as 'L4-3 Te Kuha' which was placed 'deeper' on the Bayesian phylogeny than the Neighbour-Joining, though the support for its placement is not strong on the Bayesian phylogeny. There are three major divisions in both trees, labelled as haplogroup A, B and C. Each is distinct in their molecular basis and $\mathrm{B}$ and $\mathrm{C}$ have consistent morphological features within the haplogroup that differentiate it from the others. Haplogroup B consists of several smaller morphological groups. Table 1 shows the large average genetic distances between the three haplogroups. That shows the potential for each lineage to be considered as a separate species, however the comparably large variation within haplogroup B suggests it may incorporate more than one species. 
Table 3. Average genetic variation (K2P) within and between the three haplogroups.

\begin{tabular}{lllll}
\hline Haplogroup & $\begin{array}{l}\text { Average within } \\
\text { group genetic } \\
\text { variation }\end{array}$ & $\begin{array}{l}\text { Average genetic } \\
\text { distance to } \\
\text { haplogroup A }\end{array}$ & $\begin{array}{l}\text { Average genetic } \\
\text { distance to } \\
\text { haplogroup B }\end{array}$ & $\begin{array}{l}\text { Average genetic } \\
\text { distance to } \\
\text { haplogroup C }\end{array}$ \\
\hline A & $1.73 \%$ & - & $8.09 \%$ & $11.15 \%$ \\
B & $4.17 \%$ & $8.09 \%$ & - & $10.11 \%$ \\
C & $0.16 \%$ & $11.15 \%$ & $10.11 \%$ & - \\
\hline
\end{tabular}
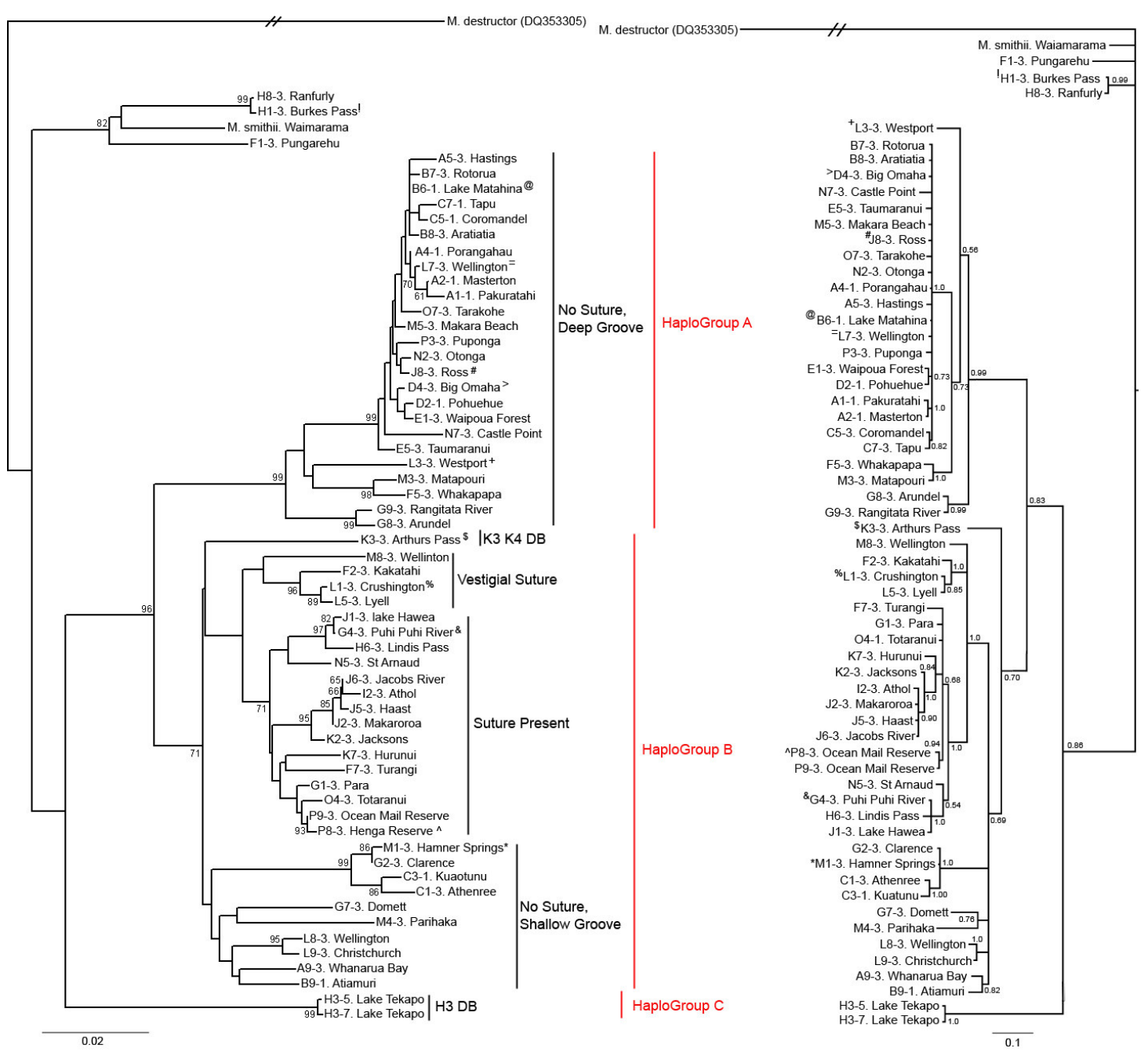

Figure 9. The two phylogenies constructed from the COI sequence data. On the left is the NeighbourJoining tree; , bootstrap support for the nodes over 50\% are shown. On the right is the Bayesian phylogeny, posterior probability support for the nodes over the equivalent of $50 \%$ are shown. The six morphological clades and the three haplogroups based on the major phylogeny splits are labelled. Identical halotypes were removed from the dataset prior to phylogeny construction; the samples with superscript symbols represent the samples seen on the phylogeny and the samples as follows; @ - M93, F4-3, E6-3, N8-3, M6-3, F8-3; = - M7-3; \# - J9-3; > - E4-3; + - L4-3; \$ - K4-3; \% - K9-3, L2-3; \& G5-3, H9-3, L6-3; ^ - N4-3, P7-3; * - I8-3, I9-3, K6-3, M2-3.

The morphological phylogeny (Fig 3) shows much the same structure as either of the molecular phylogenies, although it did result in the nesting of the clade K3 K4 DB within the clade no suture deep groove. The morphological groups aligned with the molecular phylogenies. 


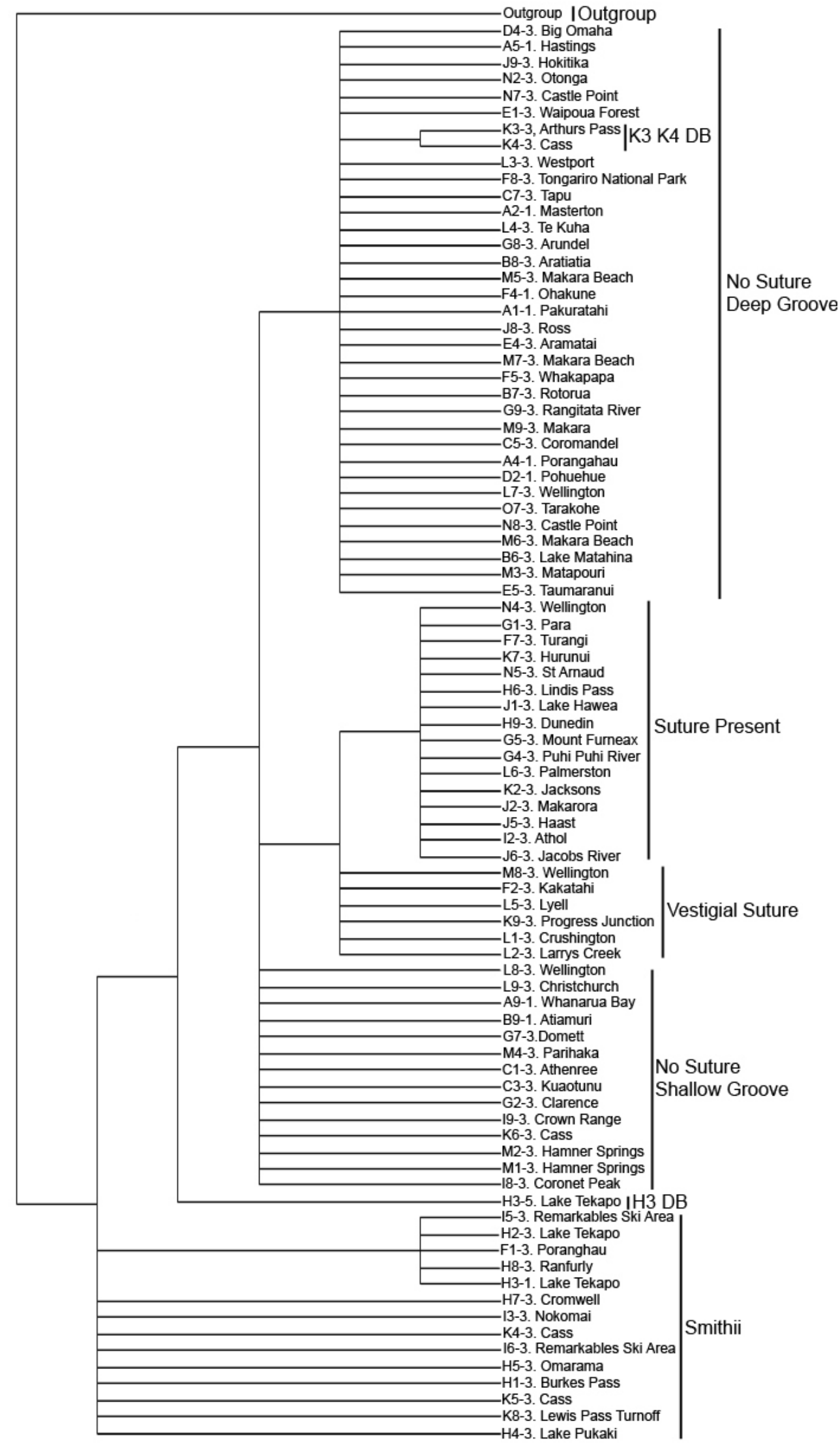

Figure 10. Maximum parsimony tree constructed from the morphological five morphological characters. Labelled are the six clades plus smithii and a theoretical outgroup. Note that there are no bootstrap values assigned to the nodes or branches as the bootstrap technique is unreliable with so few characters. 


\subsection{Geographical Groups}

There were no strong correlations of a particular morphological clade with a particular area (Fig 4). Whilst some groups tended to be associated with a particular area, such as vestigial suture, in every case there were exceptions. Identifying barriers to dispersal was restricted to the obvious marine barriers between the three islands; Cook Strait and the southern Pacific between mainland New Zealand and the Chatham Islands. The Southern Alps was discarded as a potential barrier before any analysis as although the alps have been found to be a barrier to dispersal in freshwater crayfish (Paranephrops spp.) (Apte et al., 2007) M. antarcticum samples were collected through several passes and at high altitude discounting the Southern Alps as a barrier to dispersal. Similarly latitude was discarded as the samples of the many morphological clades such as 'Suture Present' were spread almost the entire length of New Zealand (Fig 4). No biological basis for a barrier based on latitude could be found in any New Zealand fauna; hence any barrier based on latitudes would have been arbitrary, based more on the distribution of the samples collected rather than having any scientific basis. 


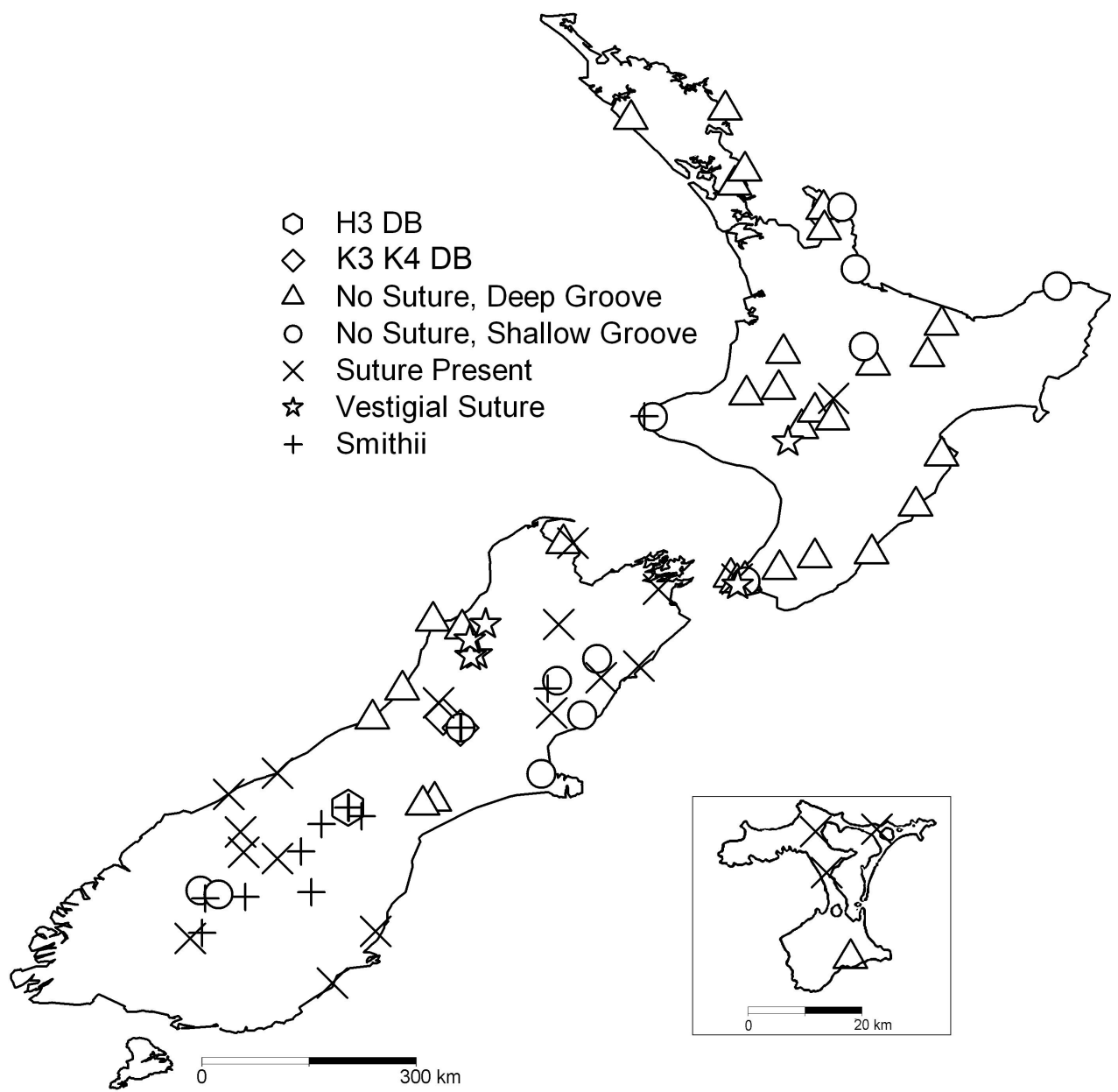

Figure 11. The locations of the samples of the six morphological clades and M. smithii. Chatham Island is shown inset, not to scale in terms of distance from mainland New Zealand. Note the spread of each individual group both within the North and South Islands and between them.

\subsection{Isolation by Distance}

There was not any significant association of genetic and geographic distance within the entire dataset, nor within either of haplogroup A or B. Whilst the RMA seems to show an association of increasing genetic distance with increasing geographic distance within the entire data set (Fig 5 a) and within haplogroup B (Fig 5 c) the association was not significant. Within haplogroup A the trend is negative (Fig $5 \mathrm{~b}$ ), an unusual result but again the association is not significant. The two horizontal 'bands' of plots seen in that figure are caused by the relatively large (for haplogroup B) genetic distance between the samples F5-3, M3-3, G8-3, G9-3 L4-3 and L3-3 (the latter not shown on the phylogeny because its sequence is identical to that of L4-3) and the rest of the samples but no corresponding increase in geographic distance hence a horizontal rather than positively sloped band of plots. 
(a)

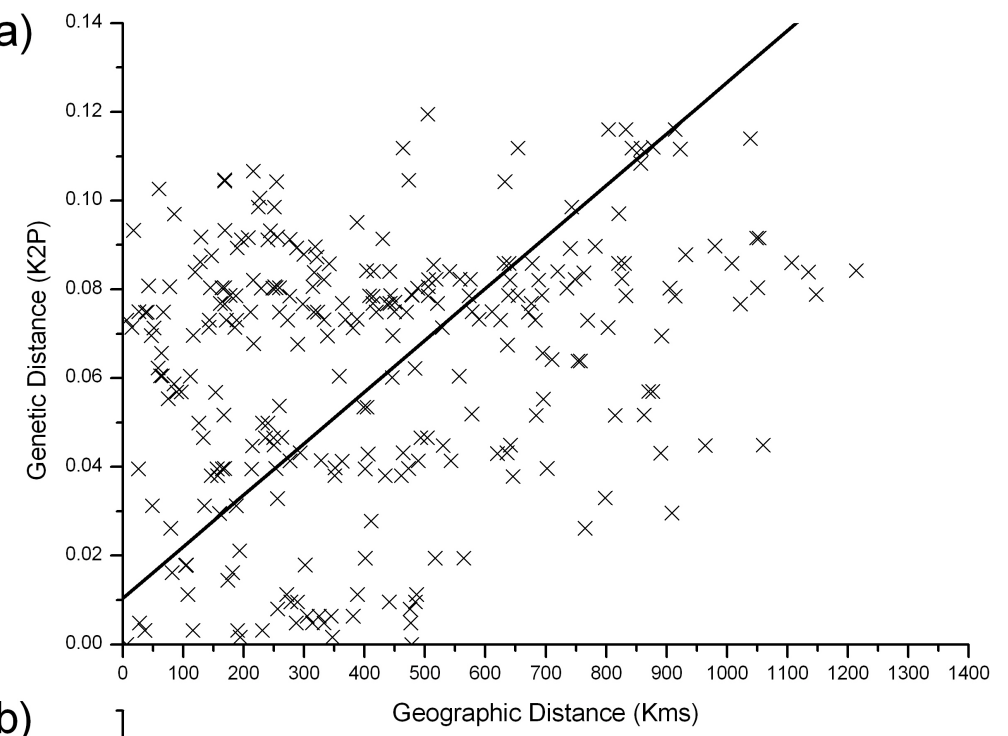

(b)

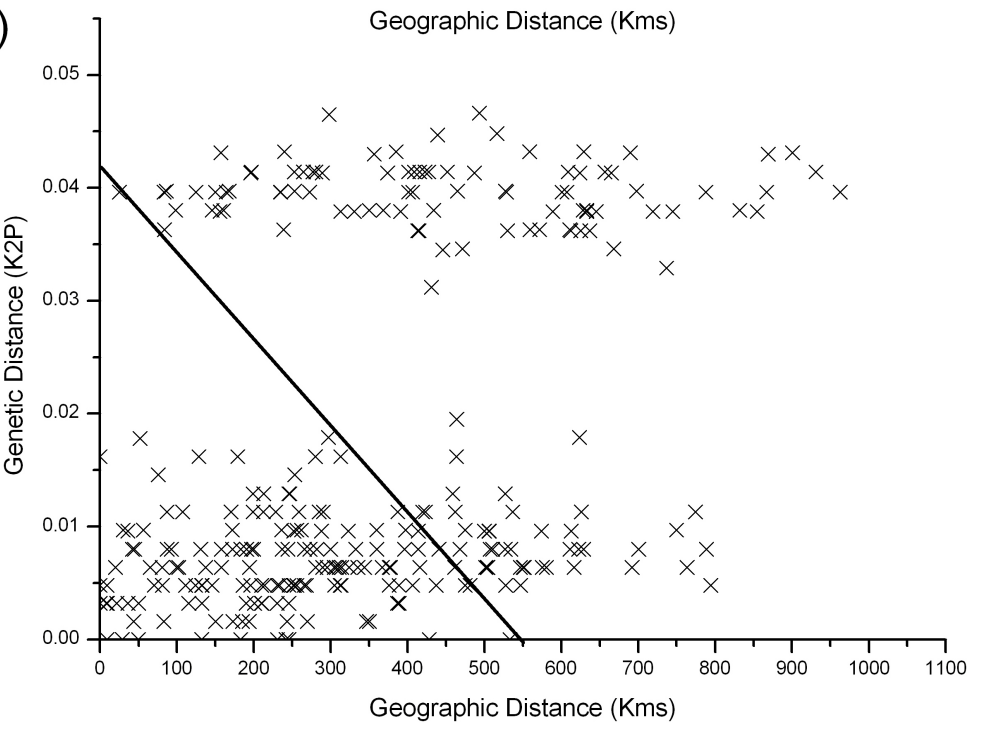

(c)

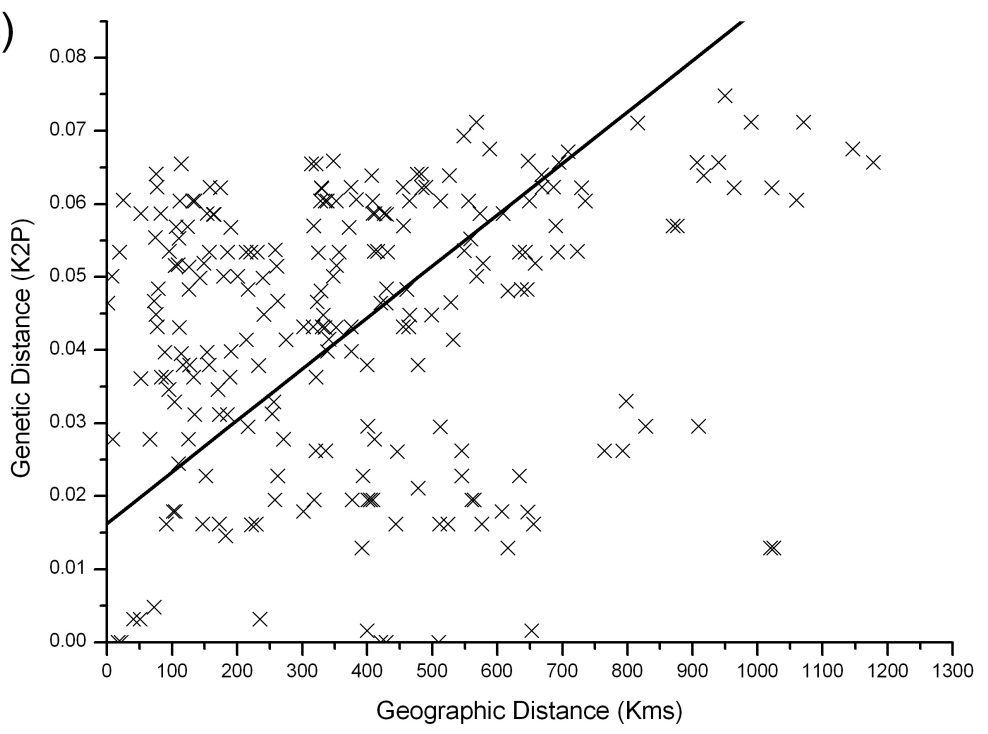

Figure 12. Scatter plot of relationship of genetic and geographic distance, the solid lines are the RMA regression lines, for all samples (a) $r^{2}=0.000169 P=0.6400$; for samples in haplogroup $\mathrm{A}$ (b) $\mathrm{r}^{2}=$ $0.00282 P=0.8200$; for samples within haplogroup $\mathrm{B}(\mathrm{c}) \mathrm{r}^{2}=0.01063 P=0.0840$. Note the association between genetic and geographic distance is not significant for any of the plots 
The fine scale plot (Fig 6) shows there is geographic overlap of morphological clades. Of particular interest are the two pairwise comparisons of samples from the same morphological group (open circles) closest to the vertical axis, both being extremely close (less than $500 \mathrm{~m}$ apart) but belonging to different morphological clades, those two pairs of samples are K4-4 and K6-3 and L7-3 and

L8-3.

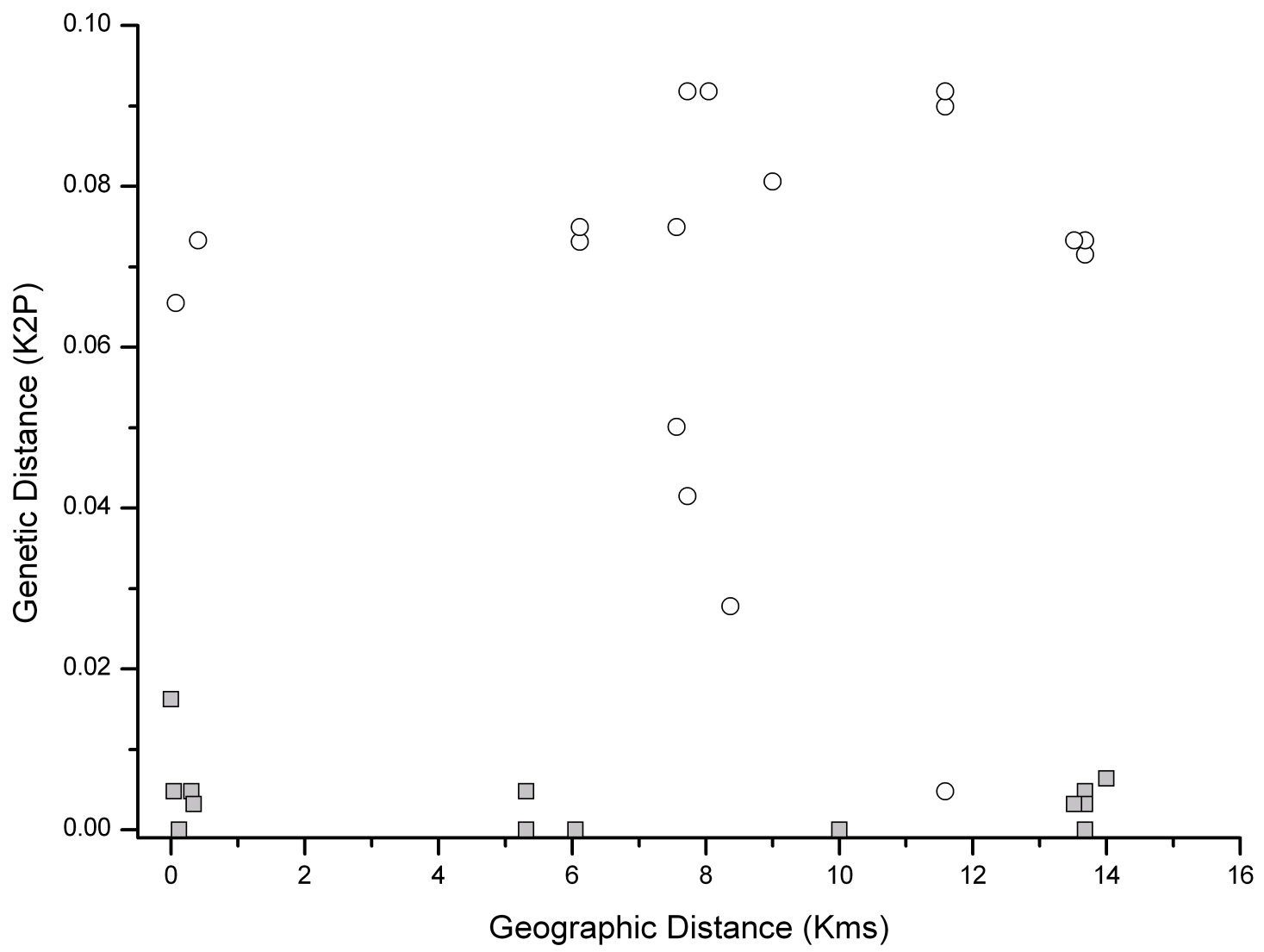

Figure 13. Genetic distance against geographic distance pairwise plot of close samples ( $<15 \mathrm{~km}$ apart). Circles are sample pairs from different morphological clades and the squares are sample pairs from the same morphological clades. Note the two open circles closest to the vertical axis showing overlap of different morphological clades on a very small $(<500 \mathrm{~m})$ scale.

There is an impressive spread of identical haplotypes across New Zealand (Fig 7). A distance of over 400kms between identical haplotypes is not uncommon, Although none of the identical haplotypes are between samples in the North and South Islands there is spread of identical haplotypes between mainland New Zealand and the Chatham Islands (the two topmost columns in Fig 7). 


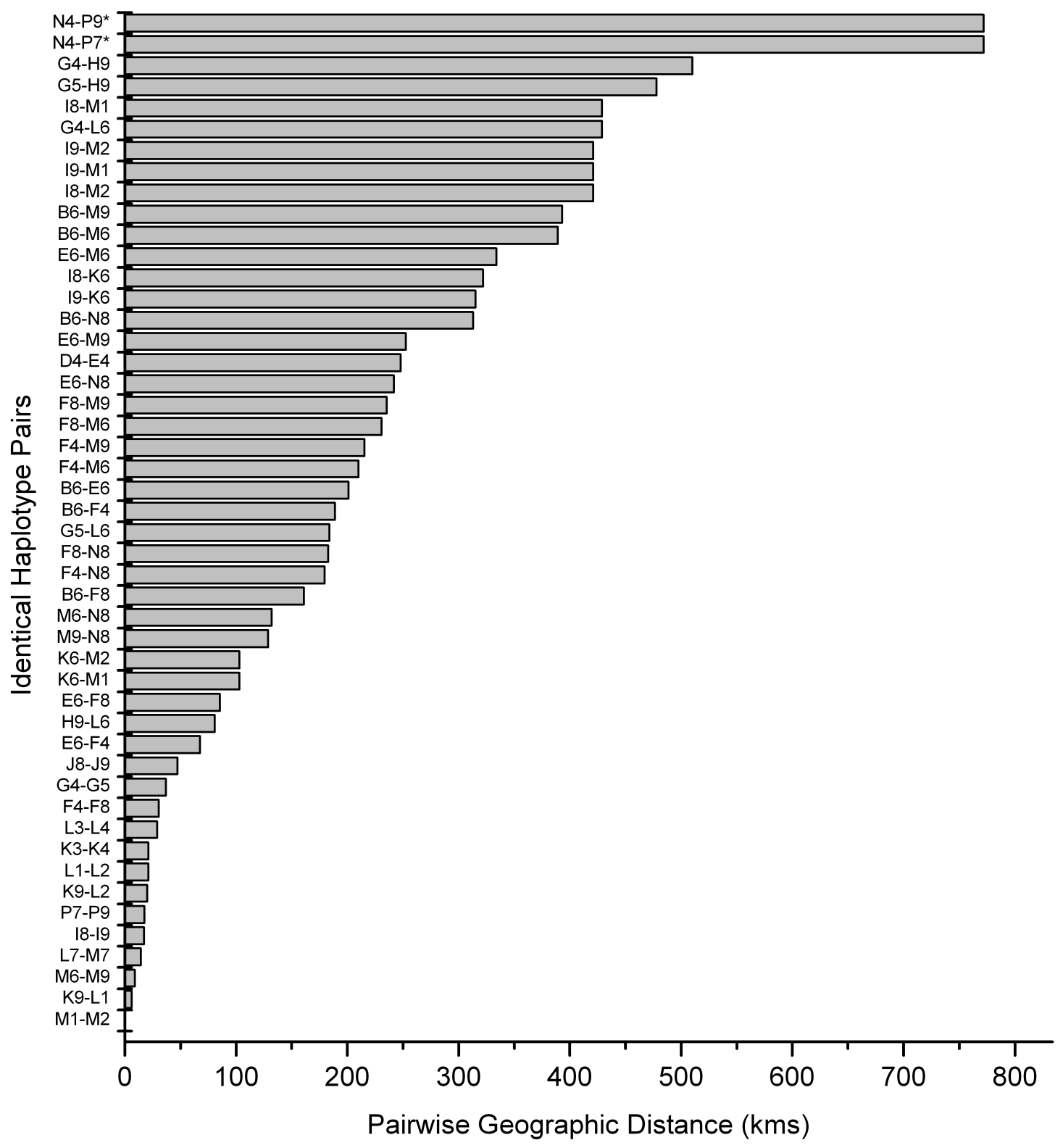

Figure 14. Geographical distance between identical haplotype pairs. The asterisks denote pairs involving a sample on Chatham Islands hence the much larger distance between those pairs.

\subsection{Analysis of Molecular Variance}

Of the four partitions of the population that could explain the genetic variation within the population, the partitioning based on morphological groups showed the highest degree of genetic isolation (table 2). The most obvious geographic barrier, the expanses of water separating the three islands where those samples were obtained proved a poor explanatory variable for the genetic variance within the data, whilst the habitat the samples were collected from seems an especially poor explanatory variable. It is not surprising the partitions based on the 
haplogroups defined from the phylogenies showed a relatively high $\mathrm{F}_{\mathrm{st}}$ value as the AMOVA employs the same data used to define the haplotypes.

Table 4. Results of the AMOVA's. Showing the four different population partitions tested, the degrees of freedom of each, the variation among the groups within that partition and it $\mathrm{F}$ value, the $\mathrm{p}$ value for many was so small as to be considered zero.

\begin{tabular}{lllll}
\hline Source of Variation & $\begin{array}{l}\text { Degrees of } \\
\text { Freedom }\end{array}$ & $\begin{array}{l}\text { Total } \\
\text { Variation (\%) }\end{array}$ & $\Phi$ & $P$ \\
\hline $\begin{array}{l}\text { Among Morphological } \\
\text { Groups }\end{array}$ & 5 & 76.74 & $\mathrm{~F}_{\mathrm{st}}=0.72461$ & 0.000 \\
$\begin{array}{l}\text { Among Islands } \\
\text { Among Three Branches of } \\
\begin{array}{l}\text { Phylogeny } \\
\text { Among Habitats }\end{array}\end{array}$ & 2 & 23.99 & $\mathrm{~F}_{\mathrm{st}}=0.23988$ & 0.000 \\
& 2 & 62.00 & $\mathrm{~F}_{\mathrm{st}}=0.61999$ & 0.000 \\
& & 6.26 & $\mathrm{~F}_{\mathrm{st}}=0.06256$ & $0.03762^{+}$. \\
\hline
\end{tabular}

\section{Discussion}

The genetic structuring seen in Monomorium antarcticum could be explained by four different hypotheses. One; the structure is due to the populations being isolated, two; the structure is due to signatures of past geological upheavals, three; the complex contains distinct species and intra-specific structuring, four; the lineages persist in the panmictic population by chance.

The explanation of the current isolation of different populations can be discarded for several reasons. The geographic spread of the different lineages points to good dispersal power and the lack of any significant association between genetic and geographic distance. Additionally the low $\mathrm{F}_{\mathrm{st}}$ value for the partitioning of the population using the North, South and Chatham Islands as a basis shows that there seem to be no current geographic isolation of the population and that the morphological groups seem genetically and morphologically isolated enough to maintain a degree of separation within the population.

The large distances between identical haplotypes and the aforementioned lack of association between genetic and geographic distance shows that $M$. antarcticum is a good disperser. As mentioned in the introduction, Solenopsis invicta, the fire ant is an excellent disperser and is very hard to exterminate due to the ability of a nest to produce numerous fertile queens and for those queens to spread over a large distance in all directions (Holldobler and Wilson, 1990). A similar pattern of dispersal may be occurring in $M$ antarcticum, whilst there are no records of within nest mating, there are records of huge mating swarms (Smith, 1895). Hence on average an individual 
queen may not be able to travel a huge distance but with a fast reproductive rate and the numbers of queens each nest can produce (Holldobler and Wilson, 1990) the dispersal potential for a lineage is substantial. As it was collected in a wide range of habitats including alpine zones that would be snow covered for long periods in winter it seems that $M$. antarcticum is able to tolerate environments that would prove barriers to many other insect species (Brower, 1994; Fairley et al., 2000). For example F5-3 was collected from an alpine beech forest near a ski resort at around 1000m above sea level whilst M3-3 a sample in the same morphological clade - and only $0.96 \% \mathrm{~K} 2 \mathrm{P}$ genetic distance apart - was collected from a beach in the far north of New Zealand over $400 \mathrm{kms}$ away. That combination of good dispersal and tolerance of a range of habitats seems to explain why there is no geographic structuring of the population. With $M$. antarcticum able to spread far quite quickly and very few true geographic barriers to impede its spread the morphological clades and haplogroups have become mixed geographically.

The population does not appear to show any geographic structuring. However, it does exhibit strong morphological and genetic structuring. The fixation of the morphology of the different clades is a strong reason to discard the hypothesis that the structuring just happens to persist in a large panmictic population. Hence the presence of more than one species and a degree of structuring based on the past geographic structure of New Zealand are the remaining explanations for the genetic structuring in the population. The presence of different species is confirmed by earlier work by this author (chapter two) and several previous studies (Brown, 1958; Don and Jones, 1993; Don, 2007; Lester et al., 2008; Smith, 1895). From that earlier work it seems haplogroups A and C (Fig 2) should be considered distinct species however there is still structuring both genetic and morphological within haplogroup B which may be due to historical geographical processes.

Past geography has contributed to structuring of other populations of native species, for example the New Zealand tree weta (Hemideina thoracica) (MorganRichards et al., 2001). In that case the population structuring is explained by the rise in sea levels during the Pliocene, 7-4 million years ago (mya), causing New Zealand to be transformed into many small islands and isolating the weta populations; the weta sub-populations are still associated with the former 'islands' and surrounding land and those sub-populations have not mixed geographically to any extent. The same basic pattern of restriction and subsequent expansion can be seen in many other 
species. This can be caused by a cooling of the climate, isolating sections of the population (Stevens and Hogg, 2003; Zamudio and Savage, 2003) (usually referred to as glacial refugia), periods of a warmer climate restricting the populations to alpine 'sky islands' (DeChaine and Martin, 2004) or the contraction of an aquatic environment (Nguyen et al., 2004). However the population structuring of $M$. antarcticum differs in that it has undergone geographic mixing and the morphological groups are not strongly associated with a particular region. Whilst there does seem to be some patterns linking geography with a particular morphological form was collected; for example samples of no suture deep groove were predominantly collected in the North Island and vestigial suture was mostly collected in the beech forests of the upper west coast of the South Island. Those patterns all had exceptions and could have been a product of the sampling regime, for example other morphological forms could have been present in lower densities and therefore not collected.

The spread of ants to the Chatham Islands is of particular interest. At around $650 \mathrm{~km}$ (at their closest) from the east coast of the North Island of New Zealand, they are situated at the eastern end of the Chatham rise, an undersea ridge extending from the eastern coast of the South Island to the Chathams. Dispersal to the Chathams would be difficult even for a flying organism such as an ant, and even harder for flightless organisms. Flightless insects such as beetles and cockroaches have been shown to have dispersed to the Chathams relatively recently (2-6 mya) (Emberson, 1995; Trewick, 2000). Both of those works raise the possibility of a land bridge linking mainland New Zealand and the Chathams sometime around that 2-6 mya period as a factor in facilitating the spread of organisms to the Chathams. The time frame for that possible land bridge does not seem to fit it with the genetic divergence shown between the mainland samples of $M$. antarcticum and those on Chatham Island. If using a conservative mitochondrial DNA evolutionary rate of $1.5 \%$ per mya as proposed for ants (Quek et al., 2004) then both lineages on the Chathams (one lineage represented by N2-3 and the other by P7-3, P8-3 and P9-3) are very recent arrivals, with all samples having less than $0.4 \% \mathrm{~K} 2 \mathrm{P}$ genetic distance between the Chatham Island sample and its closest relative on the mainland (some have identical haplotypes as seen in fig 7). This indicates the possibility of human mediated dispersal to the Chathams which is the opinion of Brown (1958). Although not known to have been spread by humans $M$. antarcticum could have been 
transported to the Chathams within a cargo of timber, plant material or raw food stuffs in recent history. Indeed human mediated dispersal is not uncommon within the Monomorium genus with several other species being dispersed by human activity (Ward et al., 2006). Alternatively the ants might have reached the Chathams very recently under their own powers of dispersal, as the genetic divergences are one order of magnitude too recent to be explained by the proposed land bridge, this would mean a minimum non-stop flight of $650 \mathrm{kms}$ or potentially rafting.

The genetic and morphological structuring of $M$. antarcticum and the dispersal patterns inferred from it could be part of the explanation for the low ant species richness in New Zealand. Good dispersal, tolerance of a range of habitats and possibly a low level of human mediated dispersal is keeping the population mixed, preventing isolation from occurring frequently and therefore slowing diversification. 


\section{References}

Allendorf, F.W., Leary, R.F., 1988. Conservation and distribution of genetic variation in a polytypic species, the cutthroat trout. Conservation Biology 2, 170-184.

Apte, S., Smith, P.J., Wallis, G.P., 2007. Mitochondrial phylogeography of New Zealand freshwater crayfishes, Paranephrops spp. Molecular Ecology 16, 1897-1908.

Avise, J.C., 1994. Molecular markers, natural history and evolution. Chapman \& Hall, New York.

Avise, J.C., Arnold, J., Ball, R.M., Bermingham, E., Lamb, T., Neigel, J.E., Reeb, C.A., Saunders, N.C., 1987. Intraspecific phylogeography: The mitochondrial DNA bridge between population genetics and systematics. Annual Review of Ecological Systematics 18, 489-522.

Baker, A., Daugherty, C.H., Colbournes, R., McLennan, J.L., 1995. Flightless brown Kiwis of New Zealand possess extremely subdivided population structure and cryptic species like small mammals. Evolution 92, 8254-8258.

Berven, K.A., Grudzien, T.A., 1900. Dispersal in the wood frog (Rana sylvatica): Implications for genetic population structure Evolution 44, 2047-2056.

Bohonak, A.J., 1999. Dispersal, gene flow, and population structure. The Quarterly Review of Biology 74, 21-45.

Brower, A.V.Z., 1994. Rapid morphological radiation and convergence among races of the butterfly Heliconius erato inferred from patterns of mitochondrial DNA evolution. Proceedings of the National Academy of Sciences of the United States of America 91, 6491-6495.

Brown, W.L.J., 1958. A review of the ants of New Zealand. Acta Hymenopterologica 1, 1-50.

Chapuisat, M., Goudet, J., Keller, L., 1997. Microsatellites reveal high population viscosity and limited dispersal in the ant Formica paralugubris. Evolution $51,475-482$.

Chepko-Sade, B.D., Halpin, Z.T., 1987. Mammalian dispersal patterns : The effects of social structure on population genetics / edited by University of Chicago Press, Chicago. 
Cook, B.D., Bunn, S.E., Hughes, J.M., 2002. Genetic structure and dispersal of Macrobrachium australiense (Decapoda: Palaemonidae) in western Queensland, Australia. Freshwater Biology 47, 2098-2112.

Cooper, A., Cooper, R.A., 1995. The Oligocene bottleneck and New Zealand biota: Genetic record of a past environmental crisis. Proceedings of the Royal Society of London: Biology 261, 293-302.

Crozier, R.H., Crozier, Y.C., 1993. The mitochondrial genome of the honeybee Apis mellifera: Complete sequence and genome organization. Genetics 133, 97-117.

DeChaine, E.G., Martin, A.P., 2004. Historic cycles of fragmentation and expansion in Parnassius smintheus (Papilionidae) inferred using mitochondrial DNA. Evolution 58, 113-127.

Don, A.W., Jones, T.H., 1993. The stereochemistry of 3-butyl-5-(5-hexenyl)pyrrolizidine from population of Monomorium antarcticum (smith) (Hymenoptera: Formicicdae) and its possible role as a unique taxonomic character. New Zealand Entomologist 16, 45-48.

Don, W., 2007. Ants of New Zealand. Otago University Press, Dunedin.

Emberson, R.M., 1995. The Chatham Islands beetle fauna and the age of separation of the Chatham islands from New Zealand. New Zealand Entomologist $18,1-7$.

Excoffier, L.G.L., Schneider, S., 2005. Arlequin ver. 3.0: An integrated software package for population genetics data analysis. Evolutionary Bioinformatics Online 1, 47-50.

Fairley, T.L., Renaud, T.M., Conn, J.E., 2000. Effects of local geographic barriers and latitude on population structure in Anopheles punctipennis (Diptera: Culicidae. Jounal of Medical Entomology 37, 754-760.

Folmer, O., Black, M., Hoeh, W., Lutz, R., Vrijenhoek, R., 1994. DNA primers for amplification of mitochondrial cyrtochrome oxidase subunit i from diverse metazoan invertebrates. Molecular Marine Biology and Biotechnology 3, 294-299.

Frankham, R., Ralls, K., 1998. Inbreeding leads to extinction. Nature 392, 441442.

Gleeson, D.M., Howitt, R.L.J., Ling, N., 1999. Genetic variation, population structure and cryptic species within the black mudfish, Neochanna diversus, an endemic galaaxiid from New Zealand. Molecular Ecology 8, 47-57. 
Gomez, A., Serra, M., Carvalho, G.R., Lunt, D.H., 2002. Speciation in ancient cryptic species complexes: Evidence from the molecular phyloegney of Brachionus plicatilis (Rotifera). Evolution 56, 1431-1444.

Hamrick, J.L., Murawski, D.A., Nason, J.D., 1993. The influence of seed dispersal mechanisms on the genetic structure of tropical tree populations. Plant Ecology 107-108, 281-297.

Holldobler, B., Wilson, E.O., 1990. The ants. The Belknap Press of Harvard University Press, Cambridge, Ma.

Hughes, J.M., Bunn, S.E., Hurwood, D.A., Cleary, C., 1998. Dispersal and recruitment of Ttasiagma ciliata (Ttrichoptera: Tasimiidae) in rainforest streams, south-eastern Australia. Freshwater Biology 39, 117-127.

Jensen, J.L., Bohonak, A.J., Kelley, S.T., 2005. Isolation by distance, web service. BMC Genetics 6.

Kelly, L.C., Rundle, S.D., Bilton, D.T., 2002. Genetic population structure and dispersal in Atlantic Island Caddisflies. Freshwater Biology 47, 1642-1650.

Kimura, M., 1980. A simple method for estimating evolutionary rates of base substitutions through comparative studies of nucleotide sequences. Journal of Molecular Evolution 16, 111-120.

Kruse, J.J., Sperling, F.A.H., 2001. Molecular phylogeny within and between species of the Archips argyrospila complex (Lepidoptera: Tortricidae). Annals of the Entomological Society of America 94, 166-173.

Kyle, C.J., Boulding, E.G., 2000. Comparative population genetic structure or marine gastropods (Littorine spp.) with and without pelagic larval dispersal. Marine Biology 137, 835-845.

Landis, C.A., Campbell, H.J., Begg, J.G., Mildenhall, D.C., Paterson, A.M., Trewick, S.A., 2008. The Waipounamu erosion surface: Questioning the antiquity of the New Zealand land surface and terrestrial fauna and flora. Geological Magazine 145, 173-197.

Lester, P.J., Dann, M.J., Ritchie, P.A., 2008. Coexistence and the use of habitat resources in a New Zealand sub-alpine ant community (Hymenoptera: Formicidae). Submitted Research. Victoria University of Wellington, Wellington.

Liautard, C., Keller, L., 2001. Restricted effective queen dispersal at a microgeographic scale in polygynous populations of the ant Formica exsecta. Evolution 55, 2484-2492. 
Loveless, M.D., Hamrick, J.L., 1984. Ecological determinants of genetic structuring in plant populations. Annual Review of Ecological Systematics 15, 65-95.

Manel, S., Schwartz, M.K., Luikart, G., Taberlet, P., 20003. Landscape genetics: Combining landscape ecology and population genetics. Trends in Ecology and Evolution 18, 189-197.

Mantel, N., 1967. The detection of disease clustering and a generalized regression approach. Cancer Research 27.

Morgan-Richards, M., Trewick, S.A., Wallis, G.P., 2001. Chromosome races with Pliocene origins: Evidence form mtDNA. Heredity 86, 303-312.

Mullis, K., Faloona, F., Scharf, S., Saiki, R., Horn, G., Elrich, H., 1986. Specific enzymatic amplification of DNA in vitro: The polymerase chain reaction. Cold Spring Harbor Symposium on Quantitative Biology: Molecular Biology of Homo sapiens 51, 263-274.

Nei, M., 1971. Interspecific gene differences and evolutionary time estimated from electrophoretic data on protein identity. The American Naturalist 105, 385-398.

Nguyen, T.T.T., Austin, C.M., Meewan, M.M., Schultz, M.B., Jerry, D.R., 2004. Phylogeography of the freshwater crayfish Cherax destructor clark (Parastacidae) in inland Australia: Historical fragmentation and recent range expansion. Biological Journal of the Linnean Society 83, 539-550.

Nylander, J.A.A., 2004. Mrmodeltest v2. Program distributed by the author. Evolutionary Biology Centre, Uppsala University.

O'Leary, M.A., Gatesy, J., Novacek, M.J., 2003. Are the dental data really at odds with the molecular data? Morphological evidence for whale phylogeny (re)reexamined. Systematic Biology 52, 853-864.

Paetkau, D., Stroebeck, C., 1994. Microsatellite analysis of genetic variation in black bear populations. Molecular Ecology 3, 489-495.

Posada, D., Crandall, K.A., 1998. Modeltest: Testing the model of DNA substitution. Bioinformatics 14, 817-818.

Quek, S.-W., Davies, S.J., Itino, T., Pierce, N.E., 2004. Evolution of host use in Crematogaster (Formicidae: Myrmicinae) inhabitants of Macaranga Euphorbiaceae). Evolution 58, 554-570.

Ronquist, F., Huelsenbeck, J.P., 2003. Mrbayes 3: Bayesian phylogenetic inference under mixed models. Bioinformatics 19, 1572-1574. 
Saitou, N., Nei, M., 1987. The neighbor-joining method: A new method for reconstructing phylogenetic trees. Molecular Biology and Evolution 4, 406-425.

Slatkin, M., 1987. Gene flow and the geographic structure of natural populations. Science 236, 787-792.

Smith, W.W., 1895. On the habits of New Zealand ants. Transactions and Proceedings of the Royal Society of New Zealand 28, 468-479.

Soares, T.N., Chaves, L.J., Telles, M.P.d.C., Diniz-Filho, J.A.F., Resende, L.V., 2008. Landscape conservation genetics of Dipteryx alata ("baru' tree: Fabaceae) from Cerrado region of central Brazil. Genetica 132, 9-19.

Sokal, R.R., Rohlf, F.J., 1981. Biometry. W. H. Freeman, New York.

Stevens, M.I., Hogg, I.D., 2003. Long-term isolation and recent range expansion from glacial refugia revealed for the endemic springtail Gomphiocephalus hodgsoni from Victoria Land, Antarctica. Molecular Ecology 12, 2357-2369.

Stöckler, K., Daniel, I.L., Lockhart, P.J., 2002. New Zealand Kauri (Agathis australis (d.Don) lindl., araucariaceae) survives Oligocene drowning. Systematic Biology 51, 827-832.

Stuart, B.L., Parham, J.F., 2004. Molecular phylogeny of the critically endangered Indochinese box turtle (Cuora galbinifrons). Molecular Phylogenetics and Evolution 31, 164-177.

Swofford, D., 1998. Paup* 4.0. Sinauer Associates, Inc. Publishers, Sunderland, Massachusetts.

Swofford, D.L., 2002. Phylogenetic analysis using parsimony (*and other methods). Sinauer Associates Inc., Sunderland, Massachusetts.

Tamura, K., Dudley, J., Nei, M., Kumar, S., 2007. Mega4: Molecular evolutionary genetics analysis (mega) software version 4.0. Molecular Biology and Evolution 24, 1596-1599.

Tamura, K., Nei, M., 1993. Estimation of the number of nucleotide substitutions in the control region of mitochondrial DNA in humans and chimpanzees. Molecular Biology and Evolution 10, 512-526.

Tero, N., Aspi, J., Siikamaki, P., Jakalaniemi, A., Tuomo, J., 2003. Genetic structure and gene flow in a metapopulation of an endangered plant species, Silene tatarica. Molecular Ecology 12, 2073-2085. 
Trewick, S.A., 2000. Molecular evidence for dispersal rather than vicariance as the origin of flightless insect species on the Chatham Islands, New Zealand. Journal of Biogeography 27, 1189-1200.

Trewick, S.A., Wallis, G.P., 2001. Bridging the "Beech-gap": New Zealand invertebrate phylogeography implicates Pleistocene glaciation and Pliocene isolation. Evolution 55, 2170-2180.

Vogt, J.T., Appel, A.G., West, M.S., 2000. Flight energetics and dispersal capability of the fire ant, Solenopsis invicta buren. Journal of Insect Physiology 46, 697-707.

Walsh, P.S., Metzger, D.A., Huguchi, R., 1991. Chelex ${ }^{\mathrm{r}} 100$ as a medium for simple extraction of DNA for PCR-based typing from forensic material. BioTechniques 10, 506-513.

Wang, X.-H., Lester, P.J., 2004. A preliminary study of the usefulness of morphometric tools for splitting the Monomorium antarcticum (smith) complex (Hymenoptera: Formicidae), New Zealand's most common native ants. New Zealand Entomologist 27, 103-108.

Ward, D.F., Beggs, J.R., Clout, M.N., Harris, R.J., O’Connor, S., 2006. The diversity and origin of exotic ants arriving in New Zealand via human-mediated dispersal. Diversity and Distributions 12, 601-609.

Wardle, P., 1988. Effects of glacial climates on floristic distribution in New Zealand 1. A review of the evidence. New Zealand Journal of Botany 26, 541-555. Willett, R., 1950. The New Zealand Pleistocene snow line, climatic conditions, and suggested biological effects. New Zealand Journal of Science and Technology $32,18-48$.

Wishart, M.J., Hughes, J.M., 2003. Genetic population structure of the netwinged midge, Elporia barnardi (Diptera: Blephariceridae) in streams of the southwestern cape, South Africa: Implications for dispersal. Freshwater Biology 48, 28 38.

Wright, S., 1943. Isolation by distance. Genetics 38, 114-138.

Zamudio, K.R., Savage, W.K., 2003. Historical isolation, range expansion, and secondary contact of two highly diverged mitochondrial lineages in spotted salamanders (Ambystoma maculatum). Evolution 57, 1631-1652. 
Chapter 4

General Discussion

Implications from the work and Future Studies 
Collectively chapter two and three have some interesting implications for the native ant diversity of New Zealand and the processes that may have contributed to the low native ant diversity. It also raises issues regarding the application of DNA barcodes in identifying new species and the integration of molecular data with morphological data used in taxonomic or population structuring studies. The two experimental chapters also suggest some further work on the Monomorium antarcticum complex and other native ant species.

\section{Implications for the Native Ants of New Zealand}

\subsection{Implications for the Monomorium antarcticum complex and the diversity of Native Ants in New Zealand}

The first chapter proves that Monomorium antarcticum is a species complex and that it consists of at least three species; the two groups with strong support and the remaining samples can be considered to be at least one species. Though with more samples and more data - morphological characters in particular - it would not be surprising if the complex revealed five or six species. This increases the native ant fauna is significantly considering there are only 11 native species currently recognised (Ward, 2005). This goes some way to removing the tag of 'depauparate' (Don, 2007) which is commonly applied to the native ant diversity of New Zealand. With the discovery of at least 3 species within the M. antarcticum complex it would be logical to do a revision of the other native ant species in New Zealand using mitochondrial DNA (mtDNA) and morphology. Such a revision would be easier with some of the results from chapter one with regards to the barcode gaps and levels of genetic diversity to be expected in related species. An initial mtDNA 'sweep' of native ant species with the same PCR conditions and primers would not be difficult or expensive and may reveal further complexes in need of revision. Monomorium smithii would be an excellent first candidate for a mtDNA 'sweep' as even from the 15 sequences used in this work there was a degree of diversity (a maximum of almost $5 \% \mathrm{~K} 2 \mathrm{P}$ genetic distance between samples) comparable to $M$. antarctcum.

Furthermore $M$. smithii has a relatively poor sample record due to it often being misidentified as M. antarcticum (Don, 2007). Whilst not the aim of this study a good 
distinguishing character to separate $M$. smithii and $M$. antarctiucm was found, the median clypeal margin. The median clypeal margin carinae of $M$. antarcticum is more distinct and produced as denticles compared to the more rounded carinae of $M$. smithii. All the $M$. antarcticum samples displayed that differentiation from $M$. smithii except for the single sample of H3 DB, that sample had a clypeal margin like that of M. smithii. That one sample of H3 DB was differentiated from the $M$. smithii samples by size, being alike in the aforementioned clypeal margin shape and coloration. Sharing those characters with $M$. smithii may indicate that H3 DB is really a sibling species of $M$. smithii and should be considered separately rather than as part of the M. antarcticum complex. Alternatively perhaps H3 DB is a hybrid of M. antarcticum and $M$. smithii, considering its exhibition of some $M$. smithii features but being in size like $M$. antarcticum. The opportunity for such a hybrid may be possible in light of the two species displaying myrmecobioses, that is nesting alongside each other (under the same rock in this case) (Lester et al., 2008).

\subsection{Processes contributing to the Low Ant (Hymenoptera: Formicidae) Diversity in New Zealand}

Compared to the rest of the world New Zealand has very low native ant diversity, our closest neighbour, Australia, has 1275 species (Bolton et al., 2006). This raises the obvious question of why is the New Zealand ant fauna so species poor? Some explanations include the temperate climate of New Zealand and the low number of distinct habitats compared to Australia (Don, 2007); New Zealand has no tropical rain forest, chaparral or desert. The latter does have some support from chapter three, as many previous sources describe the $M$. antarcticum complex exhibits a tolerance of a broad range of habitats (Brown, 1958; Don, 2007; Smith, 1895). Some of that tolerance may be due to $M$. antarcticum's nature as a complex. If, however, that tolerance of a range of habitats is typical of other native ant species then in conjunction with the lack of the contrast of habitats as seen in Australia there is less possibility for specialisation of species based on habitats. Such tolerance for differences in habitats may also contribute to the dispersal capabilities of native ants.

Being able to inhabit practically any habitat found in New Zealand means no regions can be considered barriers to dispersal. Monomorium antarcticum like most ants does 
not have the capability to disperse long distances, for instance a distance of $50 \mathrm{~km}$ is probably beyond a single queen's flight even with a strong tail wind. However as the queen could establish a colony, a second generation queen could complete such a flight or establish a colony and so on until the distance is achieved. Of course ants do not disperse in such a focussed manner but the potential to disperse long distances over many generations is possible. Comparably the arid regions of Australia could act as a dispersal barrier to many Australian species as they could not survive in the arid region nor by pass it easily. The desert regions (or any other impassable region) act as an isolation barrier.

The combined relative lack of habitat diversity, the high environmental tolerance of native species and good dispersal contribute to the low native ant species richness in New Zealand.

\subsection{Human Mediated Dispersal of Monomorium antarcticum}

There is support in chapter three for the dispersal of $M$. antarcticum by humans to the Chatham Islands, perhaps on two separate occasions with the four samples collected and analysed coming from two different molecular and morphological lineages. The spread of species incidentally by humans has implications for the conservation of species both in terms of mixing disjunct populations therefore reducing genetic diversity of the species as a whole and the potential to introduce invasive species that could threaten native species. Human mediated dispersal is a major factor contributing the problem of invasive ant species. Invasive ants can have devastating affects on the native habitat (Bond and Slingsby, 1984; Hill et al., 2003; Hoffmann et al., 1999; O’Dowd et al., 2003). As of 1999147 ant species have been recorded outside their native range (McGlynn, 1999), and five species of ants are included in Invasive Species Specialist Groups (ISSG) '100 of the worst' list of invasive species (Lowe et al., 2000). If is it possible for M. antarcticum - a species not known until now for its human assisted dispersal - to reach the Chatham Islands then there is the potential for an introduced or invasive species to reach the Chathams and disrupt the many species unique to the islands.

The impact of human mediated dispersal does not always come from invasive species. As previously mentioned, the unnatural dispersal of organism (and that is what human mediated dispersal can be considered as) can result in the mixing 
naturally isolated populations (Ellstrand and Schierenbeck, 2006; Olden et al., 2004). There may have been a genetically distinct population of $M$. antarcticum on the Chathams some time in the past progressing on its own evolutionary trajectory isolated from the mainland populations. The dispersal of mainland lineages to the Chathams may have resulted in the homogenising of that population with the mainland populations and hence a loss of the diversity previously present.

\subsection{Conservation Implications for New Zealand's Native Ants}

Most importantly this work increases the number of native ant species in New Zealand and accurate taxonomy is a fundamental in the conservation of species, quantifying the success of conservation efforts is impossible if a species is unidentified. Furthermore any surveys of ant species richness within New Zealand will be able to more accurately record the diversity present and any changes in the site in question. However there is another less obvious conservation implication from this work than the two above, the potential for native species to be used as biological barriers round ports and airports to help prevent the introduction of exotic ant species. Such a system involves the establishment of native species around ports, airports and other areas susceptible to invasion of exotic species; the native species acts as a barrier to the spread of introduced species and may allow the extermination of the exotic species whilst it is still relatively contained and feasible. A program of establishing ants around ports and airports would be more effective and easier than many other species due to their small size, relatively large area they 'patrol' (Holldobler and Wilson, 1990) and the aggressiveness many ant species display towards one another. Monomorium antarcticum displays a considerable aggressiveness towards other ant species, in particular towards the recently introduced Argentine ant (Linepithema humile) (Sagata, 2007). In addition to that aggressiveness the increase in diversity as discovered in this work and the tolerance of range of habitats would increase $M$. antarcticum's effectiveness as a biological barrier, with diversity of the native biota being one factor affecting the establishment success of exotic organisms (Kennedy et al., 2002; Tilman, 1997). In essence a program of establishing native species around areas sensitive to invasion places the newly introduced species in immediate contact with the biodiversity likely to reduce is establishment success. 


\section{Utility of Molecular Methods}

\subsection{Application of DNA Barcodes in Identifying New Species}

The utility of mtDNA sequences in taxonomic studies can be clearly seen in chapter two. Without the molecular data the results would have been less conclusive with only the morphological and morphometric data, which whilst the morphological data showed essentially the same designation of clades as the molecular data it cannot be considered ideal with only five informative characters used. However it is careful not to over emphasise the value of the molecular data, because it did have some drawbacks. Without any morphological data to provide a different perspective on the molecular results the results would have been as distinct with the matter of how to treat overlap of the barcode gaps.

The overlap of some of the barcode gap graphs is evidence of one of the drawbacks of the concept of a standard genetic percentage difference to be used to diagnose species. Considering other work and the papers on the issue of a standard percentage difference for insects it seems that the standard difference would be around the two percent mark. The application of the two percent difference to the data used in chapter would have given more, smaller clades, with most having overlap of barcode gaps and sharing morphological characters. I believe that the idea of a standard percentage difference has fundamental problems that will result in errors if the idea is applied in isolation. Species boundaries are essentially natural, whilst standard percentage differences are an arbitrary construct with no relation to the biological species concept as defined by Mayr. The standard percentage difference relies upon three major assumptions, firstly that the changes in the mtDNA sequence used are representative of the entire functional genome (an issue for all molecular data), secondly that two percent of genetic change is sufficient for two organisms to no longer to be potential mates and thirdly, all species are formed the same way and that two percent (or more) is the genetic difference between all insect species.

\subsection{Integration of Molecular and Morphological data}


Both chapters demonstrate the need for integration of molecular and morphological data. Without the layer of morphological data in chapter two the conclusions would not have been so assured, neither would the resulting clades identified be of much use to further workers on the $M$. antarcticum complex. With no morphological data the boundaries of the clades would be defined by sequence data alone. Further work on the complex in terms of testing the consistency and reliability of the clade boundaries or describing any of the clades as species would not be easy as individuals could not be assigned to a clade without DNA sequencing.

Similarly the work in chapter three would be more speculative with out the morphological data. In terms of the attributing the genetic variation to an explanatory variable the morphological groups acted as an alternative possibility to the variation other than habitat or geography. Without the morphological data it would have been more likely that the genetic population structuring would have been attributed solely to geographic upheavals resulting in isolation rather than the presence of more than one species.

\section{Further Studies}

\subsection{Future Studies on the Polygyny of the Monomorium antarcticum complex}

Polygynous nests, those with multiple queens, are not uncommon within the Monomorium antarcticum complex; several nests were collected during this work with multiple queens, one with nine queens. As mentioned in chapter three, polygyny can affect the dispersal patterns of the population; indeed there is a tendency for polygynous species of ants to be poorer dispersers than monogamous species (Holldobler and Wilson, 1990; Keller, 1993). The nests of polygnous species can be founded by 'budding' rather than by queens following mating and a nuptial flight. Also called 'nest fission' 'budding' is where one of the several queens leaves the nest with a retinue of workers to start a new nest close to the original nest (Chapuisat et al., 1997; Holldobler and Wilson, 1990; Liautard and Keller, 2001; Sundstrom et al., 2005). Such a pattern of dispersal results in highly related nests in close proximity. 
Furthermore, mating between males and newly emerged queens from the same nest have been detected (Chapuisat et al., 1997; Liautard and Keller, 2001). Without knowledge of budding and within nest mating it can affect the way potential dispersal and genetic isolation by distance is interpreted from genetic data. The high relatedness of close nests can be an indicator of the species being a poor disperser and that geographic distance is highly correlated with genetic distance. Such a pattern would be accentuated if the samples were not well spaced apart, in that the samples tended to be clusters of nests, with each cluster being geographically separate.

However assessing the degree of nest budding, within nest mating and the contribution of each queen to the brood would be relatively easy to test for. To assay the level of budding and within nest mating several 'clusters' of samples within a small area containing as many nests as possible would need to be collected, with each cluster being approximately $1 \mathrm{~km}$ apart, ideally entire nests excavated where possible to ensure collecting as many queens as possible. Then mtDNA sequences of all the queens from each nest would be sequenced. Those sequences would then be analysed using an analysis of molecular variation (AMOVA) and from that calculate a fixation index $\left(\mathrm{F}_{\mathrm{st}}\right)$ for both within and between the clusters of samples. A very low $F_{\text {st }}$ value with a high significance value within the clusters and a high $F_{\text {st }}$ value between the clusters would mean budding may be taking place or at least that few queen embark on nuptial flights of any distance (Liautard and Keller, 2001). Further work with non mitochondrial DNA would be needed to detect the level of within nest mating of queens and males.

Testing for the contribution of each queen of a polygynous nest to the brood would require a mtDNA sequence of all the queens within a nest and a sequence of many (perhaps 50 or more) workers within the nest. If the majority of the worker sequences are closely related and align with one of the queens then clearly she is the dominant or perhaps the original queen. Alternatively if the worker sequences are not all closely related and align with different queens then more than one queen is contributing to the brood. Such a data set could also reveal if any foreign queens are being accepted into the nest.

Considering that multiple queens were only found in 10 of the 25 nests where any queens were recovered it seems that the $M$. antarcticum complex is not an obligatory polygynous species. For that reason the complex would be a good model 
organism to investigate the phenomenon of polygyny, as it would be possible to study both polygnous and monogamous nests and the impact multiple queens have on the size and subsequent dispersal of the nests. Perhaps the presence or absence of polygyny differs between the species within the complex.

\section{References}

Bolton, B., Alpert, G., Ward, P.S., Naskrecki, P., 2006. Bolton's catalogue of ants of the world, 1758-2005. Cdrom. Harvard University Press. 
Bond, W., Slingsby, P., 1984. Collapse of an ant-plant mutualism: The argentine ant (Iridomyrmex humilis) and Myrmecochorous proteaceae. Ecology 65, 1031-1037.

Brown, W.L.J., 1958. A review of the ants of New Zealand. Acta Hymenopterologica 1, 1-50.

Chapuisat, M., Goudet, J., Keller, L., 1997. Microsatellites reveal high population viscosity and limited dispersal in the ant Formica paralugubris. Evolution $51,475-482$.

Don, W., 2007. Ants of New Zealand. Otago University Press, Dunedin.

Ellstrand, N.C., Schierenbeck, K.A., 2006. Hybridization as a stimulus for the evolution of invasiveness in plants? Euphytica 148, 35-46.

Hill, M., Holm, K., Vel, T., Shah, N.J., Matyot, P., 2003. Impact of the introduced yellow crazy ant Anoplolepis gracilipes on Bird Island, Seychelles. Biodiversity and Conservation 12, 1969-1984.

Hoffmann, B.D., Andersen, A.N., Hill, G.J.E., 1999. Impact of an introduced ant on native rain forest invertebrates: Pheidole megacephala in monsoonal Australia. Oecologia 120, 595-604.

Holldobler, B., Wilson, E.O., 1990. The ants. The Belknap Press of Harvard University Press, Cambridge, Ma.

Keller, L., 1993. The assessment of reproductive success of queens in ants and other social insects. Oikos 67, 177-180.

Kennedy, T.A., Naeem, S., Howe, K.M., Knops, J.M.H., Tilman, D., Reich, P., 2002. Biodiversity as a barrier to ecological invasion. Nature 417, 636-638.

Lester, P.J., Dann, M.J., Ritchie, P.A., 2008. Coexistence and the use of habitat resources in a New Zealand sub-alpine ant community (Hymenoptera: Formicidae). Victoria University of Wellington, Wellington.

Liautard, C., Keller, L., 2001. Restricted effective queen dispersal at a microgeographic scale in polygynous populations of the ant Formica exsecta. Evolution 55, 2484-2492.

Lowe, S., Browne, M., Boudjelas, S., Poorter, M.D., 2000. 100 of the world's worst invasive alien species a selection from the global invasive species database. The Invasive Species Specialist Group (ISSG).

McGlynn, T.P., 1999. The worldwide transfer of ants: Geographical distribution and ecological invasions. Journal of Biogeography 26, 535-548. 
O’Dowd, D.J., Green, P.T., Lake, P.S., 2003. Invasional 'meltdown' on an oceanic island. Ecology Letters 6, 812-817.

Olden, J.D., Poff, N.L., Douglas, M.R., Douglas, M.E., Fausch, K.D., 2004. Ecological and evolutionary consequences of biotic homogenization. Trends in Ecology and Evolution 19, 18-24.

Sagata, K., 2007. The influence of propagule size on incipient colony establishment of invasive argentine ant, Linepithema humile Mayr (Hymenoptera: Formicidae) School Biology. Victoria University of Wellington, Wellington, p. 89.

Smith, W.W., 1895. On the habits of New Zealand ants. Transactions and Proceedings of the Royal Society of New Zealand 28, 468-479.

Sundstrom, L., Seppa, P., Pamilo, P., 2005. Genetic population structure and dispersal patterns in Formica ants - a review. Annales Zoologici Fennic 42, 163-177.

Tilman, D., 1997. Community invasibility, recruitment limitation, and grassland biodiversity. Ecology 78, 81-92.

Ward, D.F., 2005. Changes to the classification of ants (Hymenoptera: Formicidae). The Weta: News Bulletin of the Entomological Society of New Zealand 30, 16-18. 